\title{
EL ALMUDÍN DE VALENCIA: UNA RESTAURACIÓN OPORTUNA PARA LA CIUDAD
}

\author{
(THE ALMUDÍN OF VALENCIA: A SUITABLE RESTORATION \\ FOR THE CITY)
}

Rafael Martínez Sánchez, Arquitecto

ESPAÑA

Fecha de recepción: 25 -II-98

\begin{abstract}
RESUMEN
El Almudín de la ciudad de Valencia es un edificio construido, fundamentalmente, a base de formas góticas y completado a lo largo de un tramo histórico que prácticamente dura hasta comienzos de nuestro siglo. Destinado a la distrioución del grano en la ciudad hasta bien entrado el siglo pasado, sirvió, desde 1908 hasta 1989, para albergar la colección paleontológica donada por J. Rodrigo Botet a la ciudad.
\end{abstract}

\section{SUMMARY}

The Almudin of the City of Valencia is a building mainly built within the Gothic, and completed along a historical stretch of time that lasts until the threshold of our century. Used as grain distribution throughout the city until late nineteenth century, it was devoted from 1908 to 1989 to house the paleontologic collection bestowed upon the city by J. Rodrigo Botet.
Aunque su valor monumental ha tenido un respaldo oficial ciertamente tarde con su declaración como monumento nacional (1969), aquél puede quedar definido en primer término por su significación civil en la historia de la ciudad, con una permanente utilidad en su existencia. Ese valor adquiere sentido por cuanto el Almudín de Valencia está enclavado en pleno espacio monumental de la ciudad histórica, dada su inmediatez al conjunto religioso y político desde los momentos iniciales de la fundación cristiana.

Recientemente, la restauración, comenzada en 1992 y concluida en 1996, ha sido galardonada con un Premio Europa Nostra de 1996 y una mención de los premios del Colegio Oficial de Arquitectos de la Comunidad Valenciana.

\section{Descripción arquitectónica y constructiva}

La construcción del Almudín a partir de 1261 en el recinto del alcázar islámico, en alguna zona abierta del mismo, según han clarificado los trabajos arqueológicos e historiográficos complementarios, adoptó, desde su origen, la configuración tipológica decidida de edificio como conjunto en torno a un patio descubierto, con, al menos, doce arcos. Sus límites físicos mảs probables fueron la cerca del alcázar islámico y algunas casas o edificaciones colindantes.
Este sistema tipológico de construir, heredado de la antigüedad y asumido totalmente por la cultura islámica y, posteriormente, codificado por el renacimiento, permite la mayor versatilidad de uso, extensión y escala. Como ha señalado A. Capitel", "estas características son las que permitieron resolver conjuntos en los que tanto el programa como los problemas de inserción en la ciudad no resultaban muy propios para configurar organismos arquitectónicos regulares o ideales". Si bien este autor se refiere en mayor medida a los edificios resueltos con el nuevo código del clasicismo, vemos tanto más adecuado explicar la opción tipológica en una etapa como el gótico, en la que no hay un planteamiento con un orden o una sintaxis normativos.

Esta versatilidad manifiesta, ha permitido la evolución cambiante, no desprovista de incidencias y dudas en el edificio, completándose hasta su extensión como conocemos a costa de las casas vecinas, fenómeno claramente habitual en las grandes construcciones civiles y religiosas de la ciudad, como tantos documentos han acreditado.

Su planta trapecial, resultante de la construcción de una crujía única vertida al patio central con seis arcos de medio punto en los lados mayores y dos en cada uno de los menores, adquiere una mayor complejidad por la 
duplicación de la crujía en el lado oriental con motivo de la incorporación de un atrio recayente a la plaza de S. Luis Beltrán.

Los accesos conocidos quedaban reducidos a dos: en primer lugar, al portal de cantería de la calle del Almudín actual, enfrentado axialmente con la calle del Peso de Harina, compuesto por un arco de medio punto con amplias dovelas y capialzado escarzano en su trasdós, que permite la transición al medio punto y la formación de galce en las jambas para el alojamiento de la portada de madera. Al parecer, esta portada quedaba protegida por un porche anterior a la fachada, compuesto por un par de esbeltas columnas de piedra que sostenían un cobertizo de madera, desaparecido en el s. XIX. Y desde la plaza de S. Luis Beltrán, se accede al edificio por un recuperado pórtico de cantería, formado por tres arcos de medio punto, de modo que el vano central tiene entre sus arcadas colindantes otros vanos menores interpuestos adintelados "a regla" de los arranques de los arcos citados. En esta fachada conviene afirmar ciertas hipótesis desde el dominio teórico de la arquitectura:

- La concepción estructural está claramente adscrita a las técnicas góticas de estereotomía de la piedra: el reparto y labra irregular de las dovelas de los arcos, con claves dobles, el biselado de las aristas hasta los salmeres, con una transición de arista viva hacia los capiteles de las columnas de fuste ochavado -de lados iguales-, cuyo pedestal posee la misma forma del capitel invertido: ambos como resultado de ochavar el cuadrado de lado aproximadamente igual al espesor del muro, con la transición de un desvanecido de cuarto de esfera desde la sección octogonal a la cuadrada envolvente. Los empujes se resuelven con la transmisión de las cargas hacia sendos estribos de cantería en las esquinas de la fachada con una fuerte traba y con un espesor reforzado del muro.

- Este pórtico parece diseñado inicialmente sin la sobreposición de fábrica de tapial con remate almenado, que se añadiría, sin duda, posteriormente a su construcción, en el contexto de las grandes obras de cubierta -con tejado generalizado-, a partir de 1571; aunque no conocemos qué intervalo pudo mediar entre estos trabajos. Esta fábrica agregada llega a trasdosar el cierre de cantería entre arcos desde la segunda hilada contada desde los huecos con dintel. Esta sobrecarga adicional de fábrica, sin trabazón con las esquinas construidas con cantería en su altura total, debió ocasionar a la larga unas deformaciones excesivas que produjeron una fuerte fisuración de la zona central, con desplazamiento de dovelas. Esta causa que amenazaba la estabilidad, junto con la prevención ante tumultos en épocas de hambre en la ciudad, quizá llevó a cegar todos los vanos a excepción del central. En la desaparecida Lonja del Aceite, se cegaron los arcos descubiertos existentes con mampostería y se les pusieron puertas en 1734, para evitar desórdenes nocturnos ${ }^{2}$, lo que hace suponer que fuera un recurso excepcional, pero posiblemente adoptado en más de una ocasión. Por otro lado, quizá el temprano cegado explica la ausencia de noticias.

- En cuanto a la significación de obra emblemática del prerrenacimiento o tardogótico valenciano, que, en algunos estudios autorizados ${ }^{3}$, se ha asignado y contextualizado por primera vez a esta parte ciertamente singular, que caracteriza la fachada oriental del edificio, coincidimos también en la inoperancia de las clasificaciones apresuradas, inmediatas o basadas en prejuicios retóricos, por lo que debemos sumar nuestra descripción e interpretación desde los instrumentos prácticamente disciplinares. El papel supuestamente pionero de la composición arquitectónica adoptada se ha otorgado casi exclusivamente por las referencias formales que permiten una comparación directa con los diseños combinados de arcos de medio punto y adintelados de codificación serliana.

- Esta fachada recuperada para la ciudad, antes de su materialidad, es composición y estructura, sin ornamento. La división del plano de fachada en diez partes iguales, permite componer una puerta con una opción evidente por el triple vano principal con arcos de medio punto, y un vano interpuesto entre cada uno de éstos, de modo que los arcos citados ocupan dos décimas partes en su luz total, y una cada machón de esquina y cada vano adintelado, respectivamente. Tales divisiones, al constituirse en ejes secundarios de la composición, definen, alternadamente, una secuencia: el apoyo de los arcos laterales en el extremo interior del machón de esquina, el eje de los arcos laterales, el eje de los pilares ochavados y el eje del arco central y de la fachada. Otra relación interesante es que los ejes de los machones de las esquinas (dos) y de cada vano (cinco), dividen la fachada en seis partes iguales a partir de los macizos laterales. Con este recurso de alternancia de los ejes de los vanos mayores y de los menores, éstos últimos quedan asociados visualmente al eje de la fachada y, por ello, al arco central. Ambos criterios de subdivisión en diez partes (ejes de apoyo de los cinco vanos y de los tres arcos), y en seis partes (ejes de todos los vanos), que significa la génesis proporcional de la fachada, tienen un referente cultural, con la consideración vitrubiana del número 10 y del número 6, como "perfectus numerus" 4 (De architectura, Libro III).

- En este punto, anteriormente tratado, ya subyace el concepto específico de las proporciones que se desprenden del trazado de la fachada. Los ejes de los tres arcos permiten centrar dos cuadrados en cada vano mayor: el mayor prácticamente ocupa cada tercio de fachada y el menor queda alojado en los $2 / 3$ de la altura de la clave y en la luz libre de cada arco, definiendo también la altura de los vanos adintelados, que es el doble de su anchura entre ejes. Pueden apreciarse las relaciones fundamentales halladas en la composición de la singular fachada, basadas 

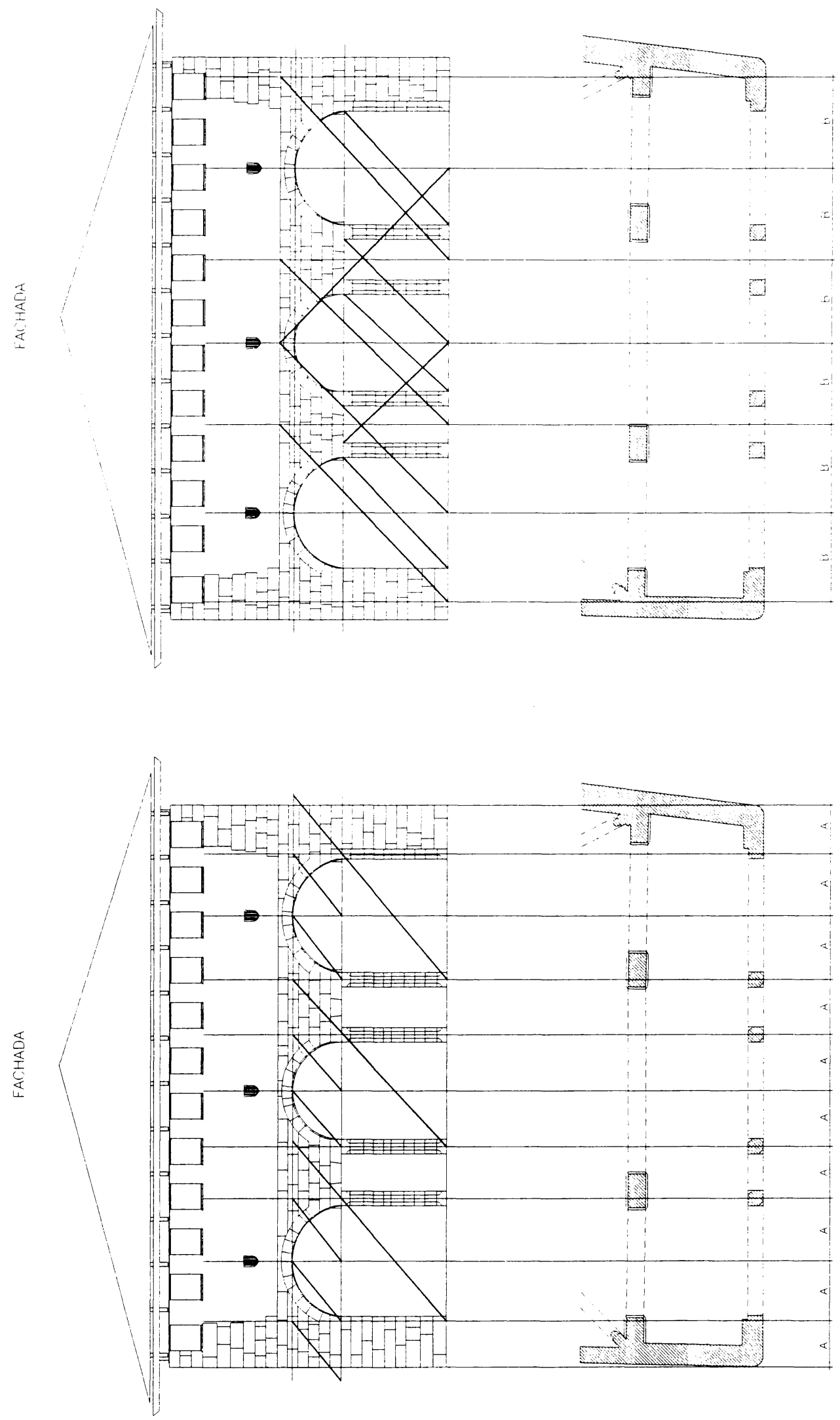
en el empleo característico de los métodos de la tradición gótica "ad quadratum", también comunes en la composición clásica, con el señalamiento de las diagonales.

Llegado a este punto esta exposición, conviene reconocer la presencia de cierta ambigüedad estilística, en esta portada del edificio. En las portadas como elemento tipológico, se concentraron los primeros ensayos de incorporación de los nuevos modos renacentistas, en la primera mitad del Quinientos sobre todo, con recurso fundamental al ornamento ${ }^{5}$, a causa de los conocimientos inicialmente fragmentarios sobre la sintaxis del nuevo lenguaje. En nuestro caso, lo característico es la ausencia de la decoración y el recurso a un aprendido o intuido esquema compositivo, basado en el diseño de los vanos como elementos capaces por sí solos de resolver la configuración de la fachada ${ }^{6}$.

Observemos que la funcionalidad del vano serliano se apoya en su favorecimiento de la iluminación y la posibilidad de extender una solución de arcada con una altura limitada, y que, de todos los órdenes clásicos o maneras de edificar, el que en este caso parece más adecuado es aquél más desornamentado y robusto: el ornamento rústico, como apropiado para puertas de ciudades, fortalezas, castillos y lugares para guardar tesoros ..., según la adecuación de los modelos serlianos (la publicación del Libro IV es de 1537). Si compararamos las puertas en la primera edición en castellano de Villalpando, de 1552, con nuestra portada restaurada es como si el artífice de la epóca hubiera usado de un arbitrio paradójicamente "albertiano" no sólo para adecuar al caso las proporciones, como de hecho admite el manual, sino para evitar decididamente la combinación de los arcos con columnas ${ }^{7}$ como propone Alberti en su libro VII (De Re Aedificatoria, 1485).

Dicho esto último con la mayor precaución, y sabiendo que la aplicación de las proporciones no ha sido durante la vigencia de los estilos normativos sino una aproximación dependiente de las licencias del arquitecto, concluimos la descripción referente a la portada de la fachada de la plaza de San Luis Beltrán, cuyo mayor valor a nuestro juicio reside en la fortuna de su elemental elaboración en el marco de la transición lingüística de aquella época.

Ya en el interior del edificio, nuestro interés debe residir principalmente en el sistema de $\operatorname{arcos}$ y en la configuración aditiva del espacio arquitectónico.

En los primeros está implícito no sólo el proceso de crecimiento del edificio, sino la propia evolución de las técnicas habituales de los canteros o pedrapiquers locales. Construidos todos ellos de cantería, a excepción de aquéllos "fosilizados", pertenecientes a accesos de casas preexistentes, o bien los que fueron abiertos con posterioridad sobre las fábricas para descargar los vanos correspondientes a ventanas de ventilación: en ambos casos las opciones recayeron en materiales cerámicos como en el caso del arco de la calle del Almudín, y también de las ventanas abiertas en 1794 en la calle Angosta, que se cubren con arco adintelado de ladrillo rematado superiormente escarzano, y que interiormente resuelve la transición con un capialzado en ventana cuadrada, de ladrillo.

Las funciones de los 27 arcos principales, que son parte sustancial de la lógica estructural del edificio, con un oficio desigual de cantería, pero con una contribución formal global muy notable, son de tres tipos:

- Los que resuelven la descarga de los vanos de muros interiores, permitiendo la gran permeabilidad espacial característica. Todos son próximos al medio punto, a excepción de los dos apuntados del lado menor occidental del patio y sus opuestos, que poseen un trazado curioso a partir de los salmeres o enjarjamientos, que confieren un aspecto algo peraltado y que, coloquialmente, se ha aproximado al arco de herradura.

- Los que admiten el acceso al edificio, abiertos en muros de fachada, ya descritos.

- Los que tuvieron una misión de sostén de forjado y de arriostramiento de la crujía única principal, que son los cuatro contrafuertes, que unen las esquinas del pórtico central, con las exteriores. Estos cuatro arcos revelan claramente el tratamiento de nervatura que se les asigna, diferenciándoles del resto no sólo por su función en la solución de las esquinas, sino por su tratamiento semejante a los nervios de bóvedas de crucería, que, sin embargo, se aproximan formalmente al trazado por arista. De todos ellos, los que poseen mayor interés por su alarde de estereotomía, como por su solución formal, son los últimos construidos, más próximos a la calle del Salvador.

Ambos son iguales, y sus 17 dovelas adquieren la misma solución que en el caso de los rincones de claustro: desde la esquina del pórtico adoptan una arista viva decreciente a partir del enjarje hasta las dos claves que son planas $\mathrm{y}$, desde éstas, forman un rincón progresivo que llega a fundirse con el que forman los muros en contacto, mediante un nuevo enjarjamiento. El labrado de la superficie de contacto entre las dovelas, a su vez, se ha efectuado por ingletes, avanzados hacia el rincón ${ }^{8}$.

Como se ha descrito, la historia de la construcción del Almudín de Valencia es consustancial al proceso aditivo de incorporación de elementos que han transformado la configuración tipológica y, por ello, espacial del edificio. Desde la ordenación de un edificio que crecía en torno a un patio hasta la sobreposición de una cubierta generalizada a finales del Quinientos, la evolución formal inmanente al edificio, ha proporcionado su imagen característica en la ciudad durante cuatro centurias, pese a una discutible 

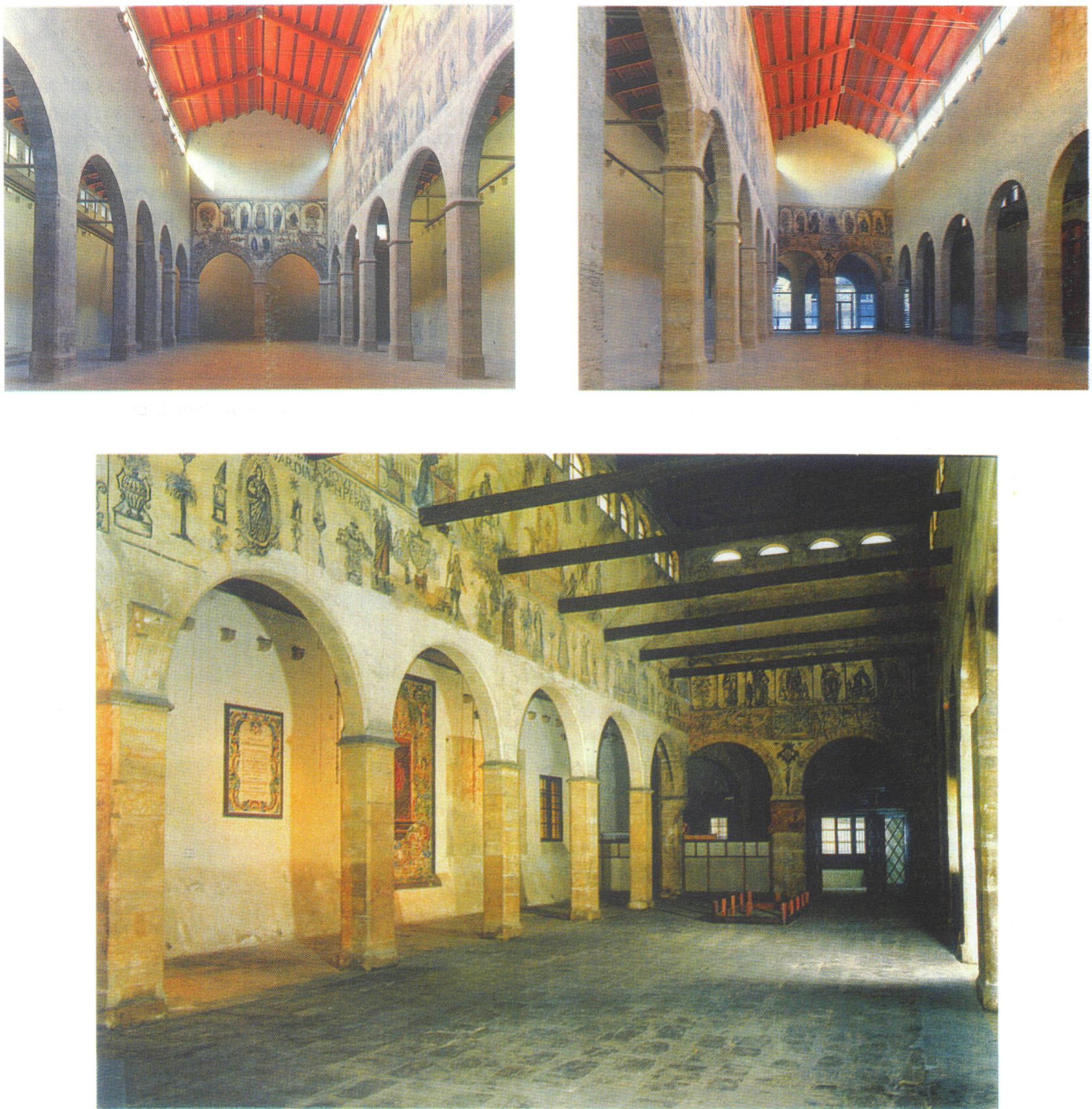

Interior del edificio, tras la actuación y anteriormente.

transformación provocada al disponer unos tejados sobre unas fábricas existentes y recrecidas que, al obedecer a los modelos basilicales, conllevó una arbitraria transformación del estado estructural inicial y, por tanto, una desestabilización del edificio, latente hasta nuestros días. Ni siquiera la gran reparación de 1874 mejoró la situación, sino que alteró la proporción de los aleros con su indiscriminado acortamiento. No sabemos qué elementos resistentes precedieron a las cerchas de madera "a la española" y al entramado elemental, que hemos encontrado y sustituido debido a su degradación. Tan sólo la descripción de Cruilles9: "la cubierta general es de embigado común", nos remite con poca exactitud al aspecto que ofrecía el entramado anterior a la renovación citada.

Esta transformación de la cubierta, con el recrecido de los muros correspondientes a los pórticos que ya definían el anterior patio central, significó no sólo una paradoja tipológica -edificio en torno a un patio convertido en modelo basilical, que también disfruta de un crédito histórico incontestable-, sino que su configuración espacial como consecuencia de ésto y su iluminación característica, cambió notablemente para derramarse sutilmente desde arriba. 
Finalmente, para concluir esta descripción claramente valoradora, no podemos olvidar los aspectos texturales de las fábricas toscas, modestas, pero consustanciales a los modos constructivos del edificio.

De los cuatro tipos de fábricas que han servido para levantar el sistema de muros del Almudín de Valencia, uno de ellos se encuentra claramente dosificado para los lugares de trabazón y absorción de empujes -esquinas y portadasy se trata de la cantería formada por sillares de piedra caliza de heterogéneo tamaño -en muchos casos reutilizados de otros edificios-. Los otros tres desempeñan un papel de materialización masiva de los muros de cerramiento:

- El más abundante es el tipo conocido como tapia valenciana o tapia real, compuesto por tierra con gravas y cal apisonada a partir de un moldeado entre tablas provistas de pasadores para su entibación, ejecutado sucesivamente por tongadas, y trabado ligeramente con hiladas de ladrillos a tizón de forma generalizada, con gruesa junta entre ellos, que en los límites de comienzo y final del paño, queda, a su vez, trabado con las esquinas o machones de cantería por medio de los mismos ladrillos colocados a soga. Tras apisonado y fraguado, el desmoldeo produce un efecto textural, al rebosar la argamasa sobre los ladrillos, que en el lienzo del muro provoca una cualidad plástica característica de esa materia superficial con efectos aleatorios de indudable valor estético. Se trata de un tipo de fábrica ya empleada desde la antigüedad clásica - muri formacei-, y habituales en nuestra ciudad durante un largo período, desde la etapa islámica, y era ejecutada por tapiadors, que junto con pedrapiquers, obrers de vila $y$ manobres, formaban el equipo usual en la construcción material de edificios, que otros oficios completaban. Este tipo de tapia se ejecutaba generalizadamente en todo el reino, como demuestra, por ejemplo, su empleo en el Palacio de Cocentaina, en el Convento de la Trinidad y en el Colegio del Patriarca de Valencia, en las murallas como las de Mascarell, o en casas populares que todavía sobreviven en el Rincón de Ademuz.

- Tapia de tierra con argamasa de gravas y mampostería, que se encuentra en la base de los muros de cerramiento del edificio, sobre todo en las fachadas de la calle del Salvador y del Almudín, en algún caso sobre fábricas semejantes de procedencia islámica, que excede en altura el zócalo usual de arranque y enlace con la cimentación de la tapia antes descrita.

- Fábrica de ladrillo macizo, de pie y medio o dos pies de espesor -con formato de ladrillo de $14 \times 28 \mathrm{~cm}$, y de hasta $15 \times 31 \mathrm{~cm}$, con mortero de cal y arena, con juntas de $3 \mathrm{~cm}$, utilizada en rellenos, reparaciones y recrecidos, ejecutada en términos generales en épocas diversas, anteriores -como las fachadas de las casas del s. XIV "fosilizadas" en el paramento de la calle del Almudín- y posteriores a la configuración de finales del siglo $\mathrm{XV}$, cegado de los vanos de la plaza de San Luis Beltrán y recrecidos de la base y de la coronación de los muros sobre los pórticos que conforman la nave central.

La apreciación de las texturas de estas fábricas anterior a la obra de restauración, como más adelante se describirá, era prácticamente imposible, debido a la degradación, al enmascaramiento que en algunas zonas enteras ocultaba la cantería o imitaba ésta, y al recubrimiento generalizado de tres fachadas exteriores -a excepción de la recayente a la calle Angosta- y de amplias superficies de las paredes interiores, con un jarrado ${ }^{10}$. Este guarnecido debió aplicarse tras la apertura de alguno de los vanos exteriores, y en todo caso hacia finales del s. XVIII, aunque se han apreciado reparaciones posteriores.

\section{Actuaciones en la restauración arquitectónica}

Un amplio conocimiento del monumento, basado en la información obtenida a través de los métodos históricos y arqueológicos y del análisis arquitectónico, ha señalado la relevancia del papel documental del propio edificio, que contiene en sí mismo el caudal de sugerencias de la actuación, proporcionando así un carácter exclusivo y
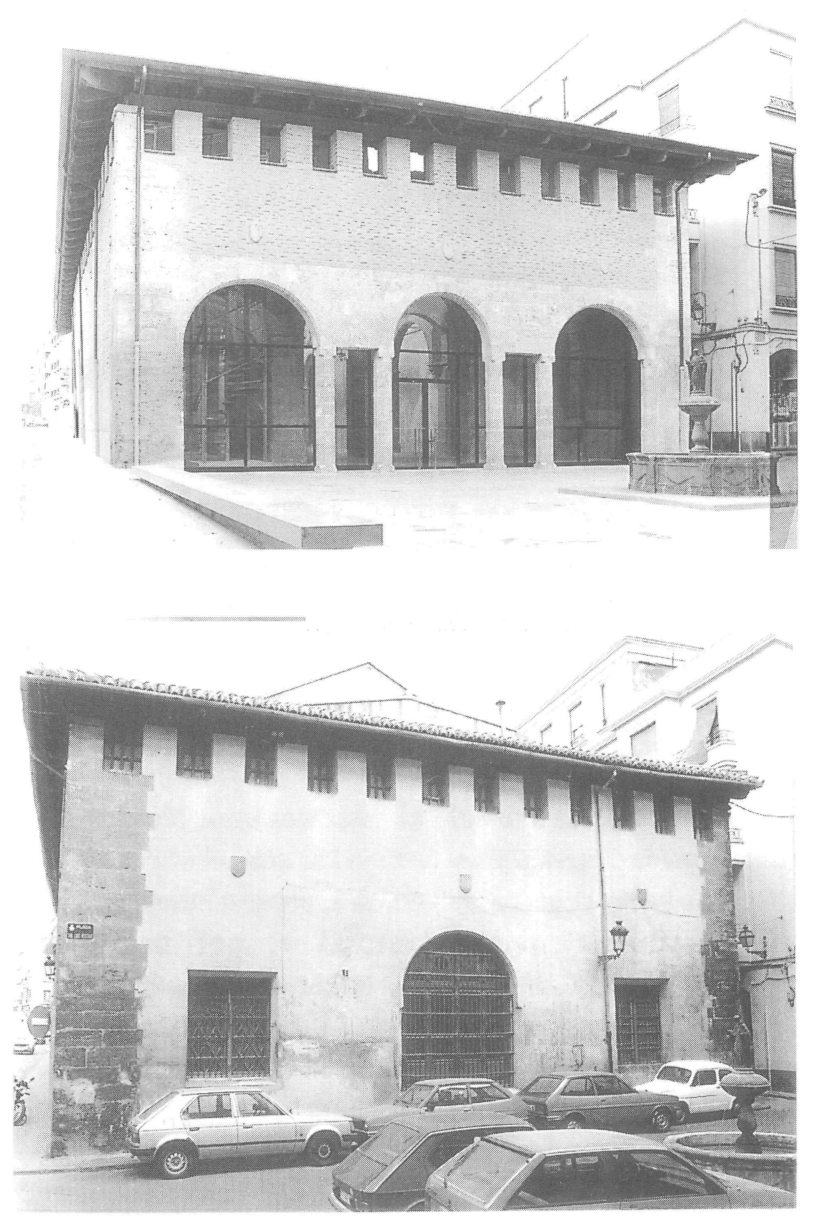

Fachada a la plaza de San Luis Beltrán. 
singular propio a esta restauración arquitectónica, que, sin duda, constituirá la primera actuación ciertamente global y coherente en el edificio a lo largo de su historia. Cada época, inevitablemente, actúa sobre los monumentos ${ }^{11}$.

La investigación histórico-arqueológica llevada a cabo antes del comienzo de las obras y durante éstas mismas, ha permitido conocer mejor los siguientes aspectos:

- Clarificación de los fragmentarios orígenes del edificio y sus sucesivas agregaciones sobre preexistencias -muros y edificaciones.

- Evolución en las grandes etapas: cubiertas, nuevos pavimentos, artes aplicadas.

- Grandes reformas constatadas, notables alteraciones de la imagen característica y del estado de las cargas gravitatorias con el consiguiente deterioro progresivo.

- Otras hipótesis, aunque vinculadas a la historia económica y local que, sin pertenecer al estricto dominio de la arquitectura, contribuyen a la explicación de los aspectos funcionales y constructivos del edificio.

En otro campo de análisis, se ha contado con el contenido del estudio geotécnico y estructural ${ }^{12}$ que ha contribuido, a través de nuestro diagnóstico, a situar y definir buena parte de la patología constructiva y estructural del edificio y, mediante su conocimiento, podemos conservar ó sustituir los elementos constructivos y estructurales, ya que las patologías detectadas identifican las alteracionesdegradaciones que han soportado esos componentes.

Los criterios de la actuación restauradora que permita leer los capítulos de una "obra abierta" de al menos seiscientos años, pueden relacionarse como sigue, tras un esfuerzo taxonómico dirigido por el orden:

1) Criterios de adecuación estructural.

2) Criterios de reparación constructiva.

3) Criterios de recuperación de las formas históricas.

4) Criterios de recuperacion de la coherencia tipológica y arquitectónica.

5) Criterios de adecuación funcional.

6) Criterios de recuperación de las artes aplicadas.

\section{Criterios de adecuación estructural}

Los problemas detectados en el sistema estructural del edificio y en gran parte desencadenantes de la actuación restauradora, consistían en:

- Desplomes en los muros situados a mediodía y fuertes agrietamientos en éstos y los correspondientes que traban ortogonalmente. Estas deformaciones diferidas han sido provocadas por la alteración del sistema original de transmisión de las cargas, por tres actuaciones relacionadas: por la eliminación de los forjados intermedios del antiguo paso de ronda, que cubría y arriostraba la crujía perimetral del edificio, por la adición de entramados inclinados de madera como soporte de la nueva cubierta, ocasionando empujes nuevos y el recrecido de los muros portantes interiores, incrementando decisivamente su esbeltez y, finalmente, por la adición de tirantes y tornapuntas de madera que han transmitido empujes puntuales a los muros del perímetro externo.

- Cedimientos en determinadas cimentaciones de los soportes de arcos y esquinas interiores, a causa de la irregularidad de la geometría y del material de asiento, que, en ciertos casos, procede de la reutilización de construcciones anteriores.

- Pésimo estado de los elementos resistentes del entramado de madera en las naves laterales y en la nave central, debido a la acción de la humedad y, por tanto, de agentes xilófagos: hongos, termita y carcoma común, concentrada en las partes empotradas: durmientes superiores de la nave central e inferiores sobre los merlones, los tirantes y los pares de las cerchas a la española. La degradación desigual de los primeros provocaba una transmisión de esfuerzos puntuales sobre las fábricas y la progresión del daño en las últimas, hubiera conducido al colapso de la estructura de cubierta superior.

- Degradación progresiva de la base de las fábricas portantes, compuestas generalizadamente por argamasas de tierras con gravas, mampuestos y cal (tapial común de las bases de los muros exteriores), así como por cantería de sillares de tamaño desigual en zonas localizadas: las esquinas del edificio, las portadas y los soportes de los arcos. Este fenómeno, ha sido producido de forma diferida por acción de las subeflorescencias originadas por humedad ascendente por capilaridad.

- Defectos de funcionamiento de diversos arcos, motivados por asiento diferencial de sus soportes o movimiento de las fábricas. Los efectos que se han manifestado son observables directamente por fisuración y desplazamiento de las dovelas o de forma menos inmediata, al descubrir los enlucidos que enmascaraban el auténtico carácter de la cantería.

En este edificio ha sido imprescindible adoptar las medidas que garantizaran su estabilidad básica, pero también establecer una tarea que consideramos fundamental en la actuación de consolidación, que se puede denominar como la clarificación del funcionamiento estructural del edificio, y se concreta en la corrección de los daños antes descritos con la adopción de las siguientes medidas consustanciales con la lógica interna de su concepción estructural específica:

- Potenciación de la concepción original del sistema de transmisión de las cargas de muros portantes y arcos: la 
recuperación de la función resistente de la totalidad de muros portantes mediante su refuerzo y zunchado, insertando con una gran habilidad manual en la intimidad material de las fábricas unas piezas de hormigón armado ${ }^{13}$ verticales en los lienzos desplomados con anclajes en la cimentación y horizontales como zunchos continuos; la reposición del arriostramiento de las crujías largas del perímetro en el nivel ideal del forjado preexistente hasta finales del s. XVI, con el recurso a un diseño diferenciado y elemental de unos tirantes de acero ${ }^{14}$, que resuelven doblemente tanto la conexión entre el muro exterior y el que descansa sobre las seis arcadas como la excesiva esbeltez, causada por el recrecido de formación de las paredes de la nave central y, por último, la valoración del papel estático del sistema de arcos, rehabilitando su misión portante, decisiva para la comprensión estructural y, por ello, arquitectónica del edificio -tanto las arcadas interiores y la portada de medio punto, como el pórtico reaparecido en la plaza, que resuelve la composición y el sostenimiento de la fachada.

Tales operaciones han partido de la opción previa de eliminación de los elementos añadidos a lo largo de la vida del edificio como prótesis extrañas al funcionamiento estructural -tornapuntas de madera empotrados en las fábricas-, que, sin añadir valores al ingenio técnológico histórico coetáneo o precedente, ocasionaban deformaciones localizadas claramente perjudiciales. Para garantizar la mejor transmisión de cargas al terreno, se optó por el recalce de la cimentación de la totalidad de los soportes de las arcadas interiores, así como de los muros de la calle del Almudín y de las alineaciones de soportes de la plaza.

- Adecuación de los nuevos elementos resistentes de madera de cubierta a su correcta posición y diseño para el orden de transmisión axial de las cargas sobre los soportes inferiores, conservando la composición básica del entramado existente (según los datos historiográficos, del otoño de 1874): cerchas con doble par y tirante y correas en la nave central y entramado de pares, correas y cabios en las naves laterales. La solución adoptada se basa en criterios analógicos, llegándose a utilizar una tecnología contemporánea homologada por la normativa española y europea en cuanto al material -madera laminada encolada de picea abies nórdica de calidad 1 y 2 según la norma DIN 4074, con uniones dentadas según la norma DIN 68140-, tirantes y mecanismos de apoyo y conexión de acero inoxidable $18 / 8$, sin ningún empotramiento en fábricas, y un método de cálculo contrastado, según la norma DIN 1052 y la norma básica española NBE-AE-88. Todos los mecanismos citados de madera y de enlace metálico han sido calculados, dimensionados y diseñados especialmente para el edificio de acuerdo con una meditada correlación de criterios: adecuación al cálculo matemático y a su lugar de acoplamiento, economía funcional y de incidencia formal, proporción relativa con respecto a su percepción y al espacio arquitectónico y, finalmente, cierta componente estética de acabado más depurado hacia las piezas de mayor importancia, caracterizada por la sensibilidad plástica basada en formas elementales. Con un concepto unitario, los entramados renovados están apoyados en un perfil IPE450, que actúa como un nuevo durmiente con rigidez mecánica suficiente para el reparto uniforme de las cargas hacia unas fábricas con un mal comportamiento frente a compresiones localizadas de cierta magnitud y, a la vez, se manifiesta rotundamente el carácter de sobreposición transformadora de la configuración tipológica del edificio que significó la instalación de tejados a finales del s. XVI.
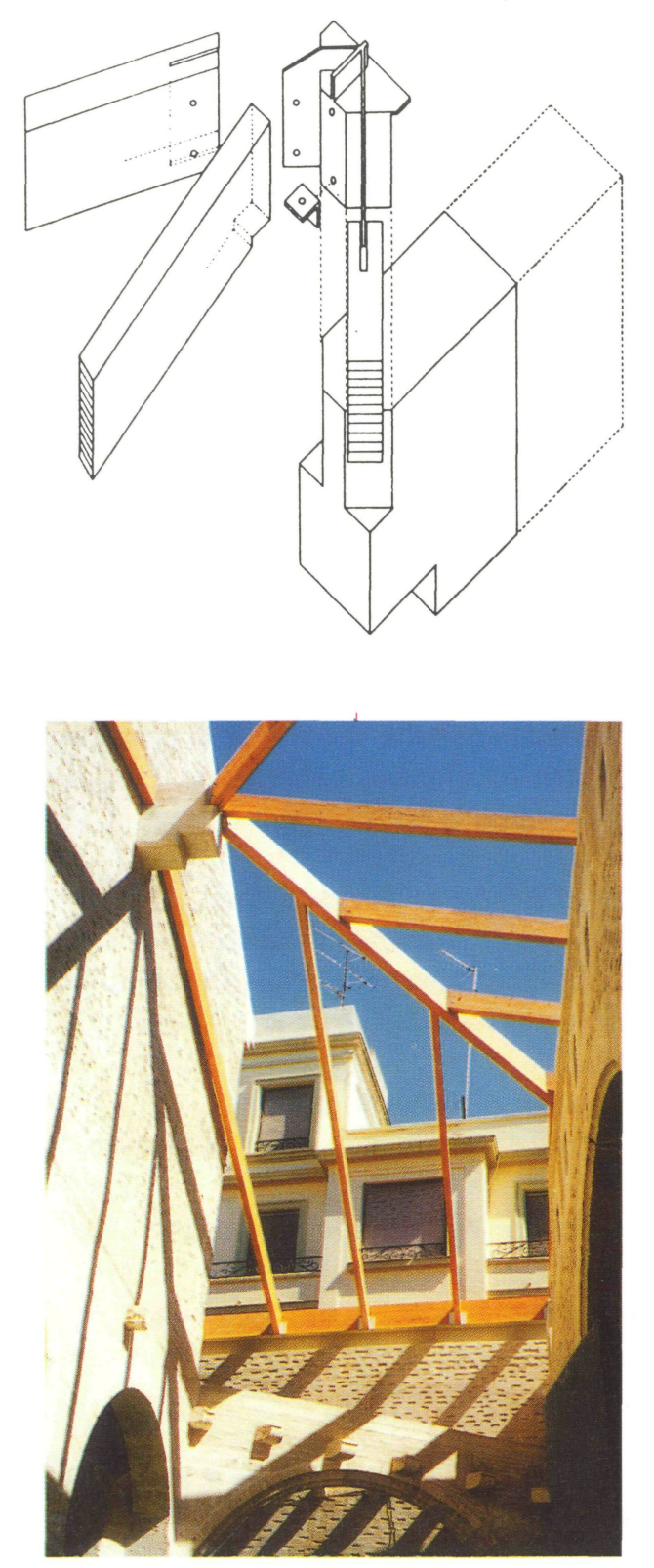

Elementos resistentes de madera de cubierta. 
Las ventajas de la solución adoptada frente a otras basadas en una técnica actualizada de aplicación lineal más o menos inmediata de lo antes existente, son:

- estáticas, debido a las mayores garantías científicas de fiabilidad de las condiciones resistentes de los materiales exigidas con arreglo a normas DIN,

- cualitativas, debido a los controles de homologación de calidad exigidos con arreglo a normativas de acreditación europea,

- configuración de un sistema constructivo autónomo y singular para este edificio, que no transmite empujes a las fábricas inferiores, pero que consigue anillar las coronaciones de muros,

- legibilidad de la solución aditiva de tejados, impuesta en una etapa de la historia constructiva del edificio (a partir de finales del s. XVI y, que conozcamos con posterioridad: finales del s. XIX y finales del s. XX, obviamente),

- ausencia de empotramiento de la madera en fábricas, que unido a sus tratamientos hidropelentes y antixilófagos y a las barreras metálicas, constituye una eficaz protección contra hongos e insectos,

- buen mantenimiento de los elementos y, por tanto, del conjunto estructural,

- conservar la identidad material básica propia de los sucesivos entramados de cubierta y gracias a las buenas prestaciones mecánicas de los voladizos, conseguir la recuperación de los aleros acortados en 1874,

- contribución a la diafanidad y esbeltez de la nave central, a la ligereza proporcionada de la cubierta, compatible tanto con la concepción gótica de las naves centrales con diafragmas ligeros y con una relevante contribución de la luz con derrame cenital, como con la configuración basilical de referentes clasicistas.

\section{Criterios de reparación constructiva}

De forma general, el criterio más adecuado en el tratamiento de los sistemas constructivos conservados o sustituidos, ha sido como sigue, descrito secuencialmente:

- conocimiento preciso de las técnicas constructivas históricas representativas utilizadas y de sus procesos de deterioro: cantería, fábricas (tapial común, tapia real o valenciana y fábrica de ladrillo), morteros de cal hidráulica y arena y formación de las cubiertas de teja árabe,

- reparación de las zonas con daños leves -sobre todo revestimientos-, con materiales contrastados, por sus características físico-mecánicas, por su compatibilidad textural y estética con las partes generales existentes en aceptable estado,

- recuperación analógica de las soluciones constructivas y de los oficios aplicados, de modo que la sustitución excepcional de los elementos en estado irrecuperable o con un grado de degradación irreversible, venga respaldada por soluciones dispositivas análogas, diferenciadas, pero con recurso a tecnología contemporánea cualitativamente contrastada.

\section{a) Cantería}

Esta fábrica se encuentra aparente en las esquinas exteriores del edificio, en los soportes y dovelas de los veintisiete arcos -incluida la portada con los tres arcos reabiertos en la fachada de la Plaza de S. Luis Beltrán-, en la portada de la calle del Almudín y en fragmentos de muros -sobre todo en la fachada de la calle Angosta-. También se considera aquí la solería interior añadida a partir de 1571 , compuesta por losas de tamaño y procedencia irregular.

Según el informe geotécnico-estructural citado ${ }^{15}$, la piedra utilizada en el edificio es una caliza de grano medio a grueso, con cierta porosidad. Está formada por cristales de calcita esparítica granular con poros no intercomunicados, color crema claro, según tabla de colores G.S.A., corresponde al $n^{\circ} 10$ y $R 7 / 4$.

En cuanto a las características físicas, el análisis ha determinado:

$\begin{array}{ll}\text { Peso específico } & 2,69 \mathrm{gr} / \mathrm{cm}^{3} \\ \text { Densidad aparente } & 1,98 \% " \\ \text { Porosidad (\% huecos) } & 26,3 \%\end{array}$

Si comparamos estas características físicas con las especificaciones de investigaciones autorizadas ${ }^{16}$ sobre la piedra como material constructivo, vemos que las características de esta roca como material son normales, dentro del grupo de las calizas ligeras.

De la inspección visual detenida y de la valoración de estos datos, podemos determinar que el proceso de degradación de la piedra no es altamente preocupante. En efecto, los daños que podemos apreciar con mayor preocupación son de tipo mecánico -agrietamientos, roturas localizadas por la junta de piezas adoveladas-, aunque también observamos efectos causados por la humedad capilar y ambiental.

Esta acción perjudicial viene causada a lo largo del tiempo por las sales solubles, principalmente sulfatos alcalinos y cloruros. La interpretación que cabe en nuestro caso, que sabemos que esta piedra reacciona con el ácido clorhídrico, es la siguiente: si en la atmósfera y procedente del terreno existe una notable presencia del ión cloruro, por acción catalítica puede transformarse en ácido clorhídrico, que 
disuelve parcialmente las partes carbonatadas de la piedra. Por otra parte, la acción de los contaminantes carbonosos y sulfurosos en el ambiente atmosférico puede causar un proceso diferido de sulfatación de la piedra caliza del edificio.

Las zonas en buen estado se han sometido a una limpieza superficial por medio de agua caliente a baja presión, con productos fungicidas, con objeto de eliminar la suciedad acumulada, una vez comprobada la inexistencia de pátinas o recubrimientos característicos, sólo presentes en algunas zonas interiores, pintadas con las figuraciones al templecola que, por otra parte, han sido protegidas y consolidadas rigurosa y cuidadosamente.

Las reposiciones con el mismo tipo de piedra caliza, han consistido en la sustitución de la pieza completa del sillar dañado de modo irrecuperable o bien por casos aislados de anteriores reparaciones consistentes en aplacados, dándose casos de formatos inadecuados con relación al aparejo dominante. En estos casos el trabajo de la superficie se ha terminado diferenciadamente con gradina de huella vertical algo más amplia que en el resto del monumento. Los efectos de la humedad ascendente, como se verá mas adelante, han sido detenidos gracias a la correlación de varias actuaciones.

El enlosado interior se hallaba colocado sobre pavimentos anteriores diversos y de canto rodado del siglo XV a los que, como la excavación determinó, deterioró parcialmente hasta el extremo de no permitir la evidencia de su extensión real. Se extendió a partir de 1571, y estaba compuesto por losas trabadas de variado tamaño y procedencia, con espesores variables de 12 a $17 \mathrm{~cm}$ sobre un lecho de tierra y cal, que alcanzaba una capa total de 30 a $36 \mathrm{~cm}$ de grosor, a costa del nivel interior preexistente que significaba inexorablemente el acortamiento de los pedestales de los soportes de las arcadas, cuya proporción original, consecuentemente, se vio alterada. El estado del enlosado, tal como se apreció al redactar el proyecto era el siguiente:

- su colocación sobre el terreno no impedía la propagación de la humedad latente del subsuelo hacia el ambiente interior del edificio,

- en la nave central, las losas de piedra de Alcublas, de color gris oscuro azulado, lejanamente parecido a la pizarra, usuales en algunas solerías de templos o edificios notables, sufrían un deterioro consistente en roturas del espesor total o en lajas, descantillamiento generalizado y reparaciones defectuosas a base de mortero de cemento gris y arena,

- en las naves laterales, sólo subsistía un enlosado original de piedra caliza dorada, con el pésimo estado antes descrito, en las crujías tras la calle Angosta, del Salvador y del tramo inmediato a la nave central tras el pórtico de la plaza, puesto que el resto se había sustituido a lo largo de este siglo por un solado de baldosa crema marfil en la nave lateral tras la calle del Almudín y por un solado de mosaico hidráulico en el espacio pavimentado tras el pórtico.

La actuación en esta parte ha consistido en dos acciones necesarias: por un lado, en la preparación de una base adecuada a la solería de un edificio que ha de cumplir determinados requerimientos funcionales en la actualidad y, por otro, sustituir el heterogéneo e irrecuperable pavimento, con análogo material, despiece y sensibilidad cromática y buenas prestaciones mecánicas.

La primera acción enunciada consiste en el sellado del relieve de subsuelo originado por la prospección arqueológica con un material granular de arena y gravas, que sirve de subbase a la solera de hormigón armado de $20 \mathrm{~cm}$ de espesor, que descansa sobre una lámina asfáltica polimérica impermeabilizante.

La segunda acción ha supuesto la colocación de un nuevo enlosado de piedra de Ulldecona de $60 \times 80 \times 4 \mathrm{~cm}$ isodomo, trabado en dirección ortogonal al eje longitudinal del edificio, debido a la óptima absorción de conflictos geométricos de la planta. Con una banda distinta de $100 \times 75 \times 4 \mathrm{~cm}$ se ha señalado sutilmente el ámbito de las alineaciones de soportes de las arcadas interiores, que en la concepción original del edificio delimitaban el patio central descubierto.

Este tratamiento descrito se ha extendido de modo similar en el espacio público conexo como voluntad decidida de insertar la actuación arquitectónica contemporánea en un contexto urbano históricamente irrenunciable. La calle Angosta ha admitido ejemplarmente un ensayo de reutilización de las losas interiores antiguas supervivientes, aptas para un pavimento exterior, coexistentes con las que forman un nuevo pavimento que, con el encintado perimetral al edificio, engloba la plaza de San Luis Beltrán. Esta plaza que ha estado vinculada a la historia del edificio, ha quedado, pues, incluida en la actuación, con el recurso a escasos elementos: la extensión del pavimento desde el interior del monumento a toda la superficie, el mantenimiento de la fuente en su centro de gravedad, coincidente con el eje de la fachada recayente y la adición de un banco elemental de la misma piedra, que rememora los asientos que estaban a disposición de los ciudadanos en el entorno próximo del edificio -como sucedía ante la portada de la calle del Almudín-.

\section{b) Fábrica de ladrillo y tapiales}

Con relación a esta fábrica característica en el edificio, por su forma de construcción y composición y por su presencia mayoritaria, definimos dos grandes tipos de deterioro:

Deterioro mecánico. Son los daños que apreciamos por causa de las deformaciones excesivas causadas por acciones 
de índole estructural: como los desplomes por acción diferida de empujes, en la fachada de la calle Almudín y su muro paralelo del pórtico interior de forma más acusada y los agrietamientos considerables en los muros de la fachada descubierta de la plaza y de la nave central hacia las esquinas SE y NO, y con menor incidencia en los muros próximos a éstas -pórtico intermedio y muros de fachada-, que llegan a tener incluso la rotura de trabazón en algunos casos y sobre cuya reparación ya se ha tratado.

Deterioro fisico-químico. Por la propia construcción de las fábricas, en ellas domina el comportamiento de las argamasas, debido a la estricta misión de relleno de los componentes cerámicos. Además de los agentes mecánicos ya enunciados, podemos observar la acción degradante de la humedad ascendente por capilaridad, pero también -cosa que se olvida frecuentemente- la influencia de aquélla que procede del exterior, bien por el ambiente atmosférico persistente o por la lluvia. En el primer caso, la humedad ascendente a través de la estructura capilar de los muros, posee en el edificio una influencia cierta en la degradación existente y progresiva de los morteros, en las zonas de arranque de las fábricas (alrededor de un metro y medio en el paramento externo en las longitudes totales), donde se aprecia, tanto interiormente como en el exterior, los conocidos fenómenos de disgregación y exfoliación por capas, con el riesgo de que se alcancen extremos de incapacidad portante por aplastamiento.

Del análisis químico del informe ${ }^{17}$ extraemos las siguientes conclusiones:

- En las catas practicadas se aprecia un exceso de humedad, más evidente, como es lógico, en los paramentos interiores del mismo muro y por encima de los valores de equilibrio ${ }^{18}$.

- La circulación y formación de sales higroscópicas, solubles o posiblemente solubles en presencia de monóxido o dióxido de carbono dan lugar a la formación de criptoeflorescencias por recristalización en los poros próximos a la superficie del muro, entendido éste como una estructura capilar; algunas de estas sales son expansivas y provocan la disgregación de los morteros, por descantillamiento o desprendimiento en lajas, ocasionado por la presión interna de recristalización. Tal efecto se ha producido por un proceso de sulfatación de los carbonatos, que produce también una carbonatación de los morteros (generación de bicarbonatos solubles).

- La presencia de yeso en las argamasas, lo que hace sospechar que se añadió yeso para acelerar el fraguado de los morteros de cal -costumbre usual hasta bien entrado el S. XIX-, lo que produce resultados expansivos -fisuras-, al combinarse los iones sulfato con la cal libre, ya que los morteros de cales hidráulicas reaccionaron con el yeso (sulfato cálcico bihidratado), resultando sulfatos y aluminatos. Estos últimos, con el agua, aumentan notablemente de volumen.
- Como se comentaba anteriormente, también la humedad exterior, con sus contenidos contaminantes clorados y sulfurosos, es un agente coadyuvante en los daños mencionados.

Las medidas que han contenido el efecto de las humedades ascendentes por capilaridad han sido efectivas hasta ahora. Creemos que su eficacia se explica por la acción combinada de actuaciones.

En primer lugar, los trabajos encaminados a conseguir un buen drenaje de la base de los muros perimetrales del edificio con el relleno de las zanjas abiertas hasta la cimentación con un material granular adecuado, la conducción por tubería del agua filtrada y la correcta conducción de las aguas pluviales a la red, anteriormente obturada en algunos puntos.

Seguidamente, se ha optado por un sistema de barrera química, en la base de los muros y soportes de todo el edificio, mediante la inyección de productos de baja viscosidad, a base de compuestos de silicatos alcalinos que, al reaccionar con la cal libre de la fábrica, se convierten en silicatos de calcio, formando una barrera horizontal al rellenar el sistema capilar de los elementos de fábrica. Además, cumple las siguientes condiciones:

- garantizar la permeabilidad al vapor de agua de los muros, favorecida por el empleo de morteros de cal hidráulica $\mathrm{y}$ arena en las fábricas originales y en las reparadas,

- ejercer una acción de endurecimiento y consolidación de la piedra o de los morteros de las fábricas restantes que han sufrido cierta disgregación por la acción expansiva resultante de los procesos de cristalización y de los efectos de higroscopicidad de las sales alojadas en los miniconductos de la estructura capilar de los muros,

- poseer buena penetrabilidad en la estructura capilar de los muros, favorecida por la práctica de orificios de $30 \mathrm{~mm}$ cada $20 \mathrm{~cm}$, al tresbolillo por cada paramento, hasta $2 / 3 \mathrm{del}$ espesor total, en la parte más cercana posible a los arranques, quedando así ocultos a la vista y más eficaces ante la ascensión de la humedad,

- no poseer efectos hidrófugos y ser capaz de admitir la aplicación de pintura con textura mineral sobre las superficies de los paramentos, para proseguir con el mantenimiento del principio básico de equilibrio de la humedad y de la acción natural de la permeabilidad al vapor de agua.

La reparación general de las fábricas constituidas por argamasas ha sido otra de las actuaciones medulares sobre el edificio, por una doble razón: por conseguir su estabilidad y por recuperar una textura consustancial con el sistema constructivo. La consolidación de estas fábricas como parte fundamental del sistema estructural ha supuesto 
conocer sus técnicas profundamente ${ }^{19}$ como ya decíamos, no sólo para decidir sobre sus características mecánicas y las medidas de refuerzo general y local, con recurso a la moderna teoría de las estructuras, sino para que, además, fuera posible el entrenamiento de personal que, conocedor del empleo de los morteros de cal y arena, fuera capaz de ejecutar partes de muros de fábrica de tapia mixta o real y restituciones parciales de la misma, dado que en la actualidad estos oficios prácticamente se han perdido por inusuales. El reconocimiento murario efectuado con métodos arqueológicos consiguió identificar claramente la extensión de las variantes de los tipos de fábricas históricas. Tras el análisis de su localización, nuestra respuesta ha consistido en:

- conocer las granulometrías de las fábricas, para obtener nuevos áridos con similar graduación a los existentes y poder, así, elaborar argamasas de cal compatibles,

- obtener ladrillos macizos manuales de similares dimensiones para incluir en las verdugadas de la tapia real, distinguiéndose por su color cerámico más rojizo que los originales de distintas épocas,

- elaborar las argamasas con cal apagada, con la dosificación justa que asegure el relleno de huecos entre granos de árido para asegurar la cohesión de mortero: se ha llegado en obra a cierta casuística, como resultado de los pesajes de medidas secas y sumergidas del mismo tipo de árido,

- establecer unos tajos de obra según los casos: restituciones y cegados de vanos con encofrados de madera machihembrada con dimensiones tradicionales, reparaciones de fragmentos notables de los muros, como aquéllos originados por la disgregación y, por último, reparaciones de las cortezas superficiales levemente deterioradas o resultantes tras el picado de los paramentos revestidos con el mortero de yeso, cal y arena generalizado, que quizá se aplicó como jarrado a finales del setecientos, sobre los paramentos que ya, por entonces, tuvieran daños localizados y, con criterio general, sobre las fachadas, puesto que en amplias zonas del interior ha subsistido hasta nuestros días la textura intacta original específica de la tapia real sobre todo, y que sirvió, ya desde los momentos de redacción del proyecto arquitectónico, para identificar un criterio de actuación sobre la recuperación de texturas características,

- conseguir el zunchado perimetral de los muros de fachada, en los niveles marcados por el antiguo forjado que, apoyado en los canecillos de piedra, habilitaba el paso de ronda tras el almenado, así como el zunchado superior de los muros interiores, siempre resuelto con piezas resistentes de hormigón armado elaborado con cemento blanco, ha sido una medida que aun comprendida en el dominio del refuerzo estructural, ha contribuido eficazmente a la consolidación de las fábricas, especialmente en las zonas de mayor degradación o deformación-desplomes y alabeos horizontales- que, con la colaboración de los soportes del mismo material resistente embebidos en la materialidad muraria y anclados en la los recalces de la cimentación, como ha sido el caso de la fachada de la calle del Almudín, ha significado la estabilización de las fábricas en unos recuadros que comparten la intimidad material y la continuidad estructural con el sistema característico del edificio. Esto significa que sobre estos elementos es posible conectar los dispositivos de arriostramiento transversal del edificio, como los atirantamientos diseñados en las naves laterales, o los aparatos de apoyo de las cerchas superiores, que también disponen de un atirantamiento con cables de acero inoxidable entre los apoyos de los pares,

- sobre las superficies terminadas -según cada textura-, como resultado externo del procedimiento constructivo de cada fábrica, se decidió aplicar una pintura protectora que garantizara la cualidad textural obtenida, la impermeabilización compatible con niveles óptimos de difusión del vapor de agua, la protección contra los efectos agresivos del ambiente atmosférico y la carbonatación $\mathrm{y}$, por último, una durabilidad y correcto mantenimiento.

Antes de concluir con esta descripción sobre actuaciones en las fábricas más representativas del edificio y, en consecuencia, con la concepción de la intervención de consolidación estructural descrita anteriormente, que en este edificio adquiere una relevancia poco común, hemos de referirnos a uno de los caracteres más directamente relacionados con las concepciones históricas de la construcción en tanto que ciencia empírica en las grandes etapas del edificio y de su arquitectura: el espesor de las fábricas, como variable relacionada directamente con la estabilidad. Esta dimensión ha quedado inalterada en nuestra actuación, y nos consta que al menos ha llegado hasta nuestros días como una manifestación de la materialidad del inmueble desde su primera configuración completa a lo largo de la segunda mitad del cuatrocientos. En esa etapa medieval, la realización del sistema murario residía en el obrer de vila, que debía atenerse a las reglas del arte de su oficio constructivo que, con una correcta ejecución, garantizara el monolitismo y la nivelación de las fábricas. Hasta bien entrado el siglo XVIII, la resistencia de los materiales se concebía como durabilidad, lo que explica que en la mayoría de los casos de las fábricas históricas la capacidad resistente no sea defectuosa. En la historia, el lenguaje constructivo ha sido una de las manifestaciones de la condición cultural de una sociedad $^{20}$.

Si bien hasta el gran desarrollo de la mecánica estructural del siglo pasado, la manualística no permitía construir con el soporte matemático aplicado, tratadistas como J. Rondelet, basaron su análisis estructural en métodos de observación extraídos de las ciencias naturales: sobre un número de casos estudiados, se extrae una experiencia ${ }^{21}$. Por primera vez, un corpus científico trata de determinar 
las formas y dimensiones que deben darse a las partes de los edificios para asegurar su solidez. A partir de este cuerpo teórico-experimental, durante más de un siglo, maestros de obras y arquitectos han basado sus consideraciones dimensionales de los espesores de los muros de los edificios en las fórmulas empíricas que introducen ciertas condiciones de estabilidad ${ }^{22}$, a partir de los arriostramientos entre muros conexos, por tejados o elementos constructivos laterales. Estas formulaciones introducen por primera vez dos variables principales: las alturas de los tramos de muros afectados y la distancia entre ellos.

Con este bagaje teórico, un arquitecto del último cuarto de siglo pasado, hubiera podido intervenir en operaciones de consolidación en el Almudín valenciano, con tres tipos de actuación:

- comprobar los espesores de los muros en función de su esbeltez,

- adoptar medidas de arriostramiento correctoras en las alturas intermedias de los muros de la nave central para ajustar proporcionadamente la esbeltez por encima y por debajo de aquél (por ejemplo, atirantamiento de los muros de la nave),

- asegurar la correcta ligazón entre los muros a través de una cubierta.

La referencia al tratado del teórico francés no es gratuita, en la medida que el texto analiza en el artículo II, entre otros, casos de edificios religiosos de tipología basilical, con un esquema de la sección parecido como San Pablo Extramuros o Santa María Mayor en Roma.

Situándonos ya en el contexto de nuestra actuación es oportuno valorar el avance de la teoría de las estructuras a lo largo de nuestro siglo, pero tambíen comprender las actitudes teóricas que en la historia han garantizado buenos resultados $\mathrm{y}$, muchas veces, la supervivencia de los edificios que apreciamos.

Finalmente, pensamos que esta reflexión sobre la organización estructural ha sido procedente, por cuanto forma parte de la actitud intelectual que ha vertebrado la actuación arquitectónica y se ha reflejado clara y decididamente en el resultado formal, porque en nuestro caso era tan necesario el refuerzo general como la demostración del funcionamiento estructural, con el fin de explicar la configuración singular de este magnífico edificio.

\section{Criterios de recuperación de las formas históricas}

Ante todo, procede una breve descripción histórica sobre la consideración de los valores arquitectónicos del edificio restaurado:
- los almudines o alhóndigas siempre han estado -incluso en época islámica- en las posiciones centrales de la ciudad, cerca de la mezquita mayor o de la catedral, incluso recayentes a las plazas mayores,

- en nuestro caso, el edificio fue fundamentalmente construido en la etapa gótica, pero ha sido objeto de un proceso aditivo en su configuración arquitectónica progresiva, desde la formación originaria en torno a un patio descubierto con arcadas, ampliada a lo largo del s. XV, hasta su evolución que recuerda inequívocamente los tipos basilicales, como resultado de la sobreposición de los tejados hacia fines del quinientos,

- otro aspecto, en el que coinciden historiadores autorizados como Lámperez, Torres Balbás o Fernando Marías, más recientemente, es que la mayoría de las alhóndigas o almudines, y alguno de ellos cita en concreto al Almudín valenciano, son edificios de reducido tamaño, construcción modesta, que tienden a cerrarse al exterior para defender la mercancía y que, en pocas ocasiones, tienen sus portadas intención artística, existiendo más de uno de ellos en las ciudades importantes. Parece que está claro, pues, que dominaba el aspecto utilitario sobre el valor monumental o emblemático conferido a otros edificios de carácter religioso o civil.

En los momentos de auge constructivo inicial de la ciudad mercantil, ya entrado el siglo XV, durante más de ciento cincuenta años, durante la etapa de construcción del Almudín con patio abierto, se encontraba en sus procesos de gran reforma o configuración sustancial de grandes piezas de la arquitectura que, en gran parte, hoy subsisten como conjunto monumental: la torre de la Catedral y el final del cimborrio, la lonja de Contratación -declarada recientemente patrimonio de la Humanidad-, la lonja del Aceite, la casa del Peso de la Harina, la capilla de los Reyes del conjunto de Santo Domingo, la Generalitat, la casa de la Ciudad, el Palacio de la Inquisición, el Hospital de Pobres Inocentes, las puertas de Serranos, de Quart y del Portal Nou, el monasterio de la Trinidad y numerosos palacios privados, por referir unos ejemplos más representativos y apreciados, que situaban a Valencia como una gran ciudad europea.

Queda, pues, claro, que en el caso del Almudín, no hubo pretensión aparente de representatividad artística y monumental de la institución, predominando su función mercantil y utilitaria, perfectamente perceptible por cualquiera que abstraiga la imagen del edificio aproximada, resultante de eliminar las cubiertas y el cuerpo emergente en ellas.

Por otra parte, la imagen característica que conocemos, no es exactamente la original, puesto que, según todos los indicios históricos, el edificio se cubrió a finales del S. XVI, al parecer al tiempo que se procedió al enlosado interior, decisión nada extraña si se conoce la adversa climatolo- 
gía que sufrió Valencia a lo largo del siglo XVI, concretada en más de una veintena de avenidas del rio Turia a lo largo de casi cien años y la pluviosidad y bajada de temperaturas pertinaz de la segunda mitad de la centuria, cuyos efectos en un edificio que albergaba la principal subsistencia de la ciudad eran decisivos ${ }^{23}$.

Apreciamos, pues, que con la transformación tipológica acaecida al final del quinientos, se alcanzó cierta ahistoricidad, cierto carácter de basílica intemporal y, en cierto modo, un edificio sin voluntad estilística; baste apreciar que a una identificable fábrica gótica se asoció un cuerpo de fábrica calada con pequeños arcos rebajados, que quizá inicialmente fueran simples dinteles con soportes delgados, como era usual en el techado de los sobreclaustros -como en el Convento de la Trinidad, sin ir más lejos, o el Monasterio de Pedralbes-, o pequeños arcos de medio punto, sin nada que ver con las logias de los áticos de algunos palacios urbanos en el ámbito de la antigua Corona de Aragón, porque éstas eran una parte de la composición arquitectónica de la fachada y porque definían concretamente el último nivel del edificio, al que servían directa y exclusivamente, cumpliendo, aquellos vanos, una clara función de iluminación desde arriba, como linterna continua del espacio de mayor escala del edificio, que es sustancialmente lo que ha tenido relevancia en la intervención concluida.

Finalmente, poseemos datos elocuentes de que la eliminación de los aleros en la renovación de las cubiertas, a partir de 1874, afectó a la imagen característica del edificio y, aunque no conocemos el alcance de estas obras, que debieron ser de importancia, sabemos que esta reforma tuvo cierta contestación en la ciudad, si examinamos la prensa de la época. Pues bien, la actitud que se ha sostenido tras el conocimiento de los caracteres formales relevantes, es la siguiente:

- Consideración de la arquitectura del edificio con su calidad artística comparativa, de forma que la actuación reitera la valoración tipológica y de las soluciones arquitectónicas presentes en el edificio, del que existen escasos ejemplos supervivientes de la entidad que apreciamos en este caso en las ciudades europeas, cuando se trata de edificios medievales del comercio.

- Disposición de las cubiertas con una mejor solución de entrega sobre los merlones y sobre el dintel de la faja continua de vanos superiores, ilustrando su valor aditivo, recuperando la proporción de los vuelos y rectificando ortográficamente el trazado de la vertiente hacia la plaza, que ofrecía una solución extrañamente híbrida, contradictoria y ausente de cualquier otro interés, por incapaz de leer la única doble crujía del edificio, resolver las vertientes hacia la plaza con un faldón único como en el resto o por adoptar una confusa solución parcial: conferir el papel de muro testero intermedio al que se sitúa tras la fachada de la tantas veces citada plaza. La solución adoptada, completa la sobreposición históricamente consolidada en las naves perimetrales, con un trazado coherente de cuatro aguas, que ofrece claramente la lectura unitaria, de la que emerge el pabellón de cubierta de la nave central, a dos aguas, con sendos muros piñones.

- Apertura de la portada cegada del acceso desde la plaza de San Luis Beltrán.

- Valoración imprescindible de una planta diáfana, incapaz de admitir ninguna compartimentación horizontal o vertical.

- La apertura de las almenas a la luz, tras su tosco tabicado que ocultaba el verdadero carácter del cerramiento.

- Recuperación de la portada adovelada de medio punto con capialzado trasero.

- Adopción de una plementería de madera y cerámica, como entramado y soporte de los nuevos faldones de la cubierta de teja, con un despiece análogo al preexistente.

- Recuperación del nivel original del pavimento del edificio, antes de su pavimentación de finales del S. XVI, que significó el acortamiento de la parte emergente de los pedestales de las pilastras de piedra de la nave y, por tanto, de la proporción original de los pórticos, mediante colocación de un nuevo pavimento isodomo de losas de piedra caliza, que atiende las razones de similar tamaño y despiece, y una decidida opción de equilibrio cromático y textural -color dorado terroso, entonado con lo que existe-, evitando el excesivo pulido superficial.

\section{Criterios de recuperación tipológica y arquitectónica}

Siguiendo en este caso con la relación de decisiones conductoras de la actuación arquitectónica que atienden a razones de recuperación o provisión de mayor coherencia a los valores tipológicos y arquitectónicos, relacionamos:

- la intención global de la actuación, trata de conferir la mayor claridad y comprensión de la configuración basilical, aceptada como aquélla que procura al edificio su aceptación social actual,

- la apertura a la luz de las almenas perímetrales tabicadas y eliminación de los vanos de fachada abiertos en diversas épocas, para asegurar mejor ventilación, que hemos considerado no sustanciales, y extraños a un edificio defensivo de las subsistencias que albergara en su tiempo,

- la corrección del trazado de los faldones de las cubiertas, con resolución y valoración de los conflictos provocados por la transición de doble crujía, con un doble piñón en la 
zona que da a la plaza de San Luis Beltrán y que ya hemos descrito antes suficientemente,

- la corrección distributiva de las cerchas de la cubierta superior, la mejora de su diseño estático y plástico y, como se ha dicho, la óptima disposición del entramado auxiliar, adoptando una combinación de materiales tradicionales: madera y cerámica vistas y teja árabe de cobertura,

- la disposición mediante un diseño elemental basado en la calidad de ajuste y oficio sobre el hierro calibrado macizo, la lógica funcional, el cálculo estático y cierta neutralidad dimensional y lingüística ante la presencia de fábricas elementales, que ha caracterizado la incorporación de la cerrajería nueva. Con este material, hemos introducido, con afán evocador, una galería de mantenimiento, en cierto modo, como recuerdo del paso de ronda tras las almenas que hubo en su tiempo,

- el tratamiento cromático general del edificio, que valora las gamas de las tierras, como color dominante, al que se sujta todo elemento pétreo o metálico como la cerrajería de refuerzo. El resto de los elementos mantiene su coloración sustancial: madera, cerámica, acero inoxidable, cobre de los colectores y bajantes pluviales, acero laminado de las carpinterías.

\section{Criterios de recuperación funcional}

Constan aquí aquellos criterios que confieren unas mejores condiciones funcionales al edificio, en tanto que adecuación a su uso público, acorde con su configuración tipológica específica:

- acondicionamiento constructivo y ventilación natural, estanquidad contra la lluvia y protección contra los efectos perniciosos de la humedad capilar y ambiental,

- la incorporación de unas instalaciones técnicas actuales y adecuadas: de baja tensión, de iluminación interior programada -con lámpara de halogenuro metálico en las naves laterales y de sodio blanco en la nave central-, de agua potable para baldeo, de protección contra incendios y de seguridad contra la intrusión,

- como orientación general, la adecuación de un magnífico espacio diáfano por propia naturaleza, con una renovada vocación civil, dentro de lo que se ha dado en llamar circuito museístico de la historia de la ciudad, compuesto por:

- Los espacios arqueológicos centrales de la ciudad antigua.

- El palacio del Marqués de Campo.

- El Almudín de la ciudad.

\section{Criterios de recuperación de los oficios aplicados}

Tras las fachadas de la calle del Salvador y de la calle Angosta, existían unos retablos cerámicos polícromos, de finales del siglo XVIII, recibidos directamente sobre los paramentos. Los efectos expansivos y la degradación de las fábricas de soporte ya descritos, provocados por la acción de la humedad ascendente por capilaridad y ambiental, junto con el contenido de yeso como acelerador del fraguado de las argamasas de cal hidraúlica, dañaron considerablemente el soporte inmediato de las piezas cerámicas, que, en algunas porciones de la superficie, aparecía disgregado o abolsado, afectando la integridad de algunas piezas, con grave amenaza progresiva para el resto.

Ante tal situación, se procedió a desprender las piezas por restauradores especializados con técnicas adecuadas, a numerar y clasificar su posición relativa -incluidos fragmentos- y a transportar al Museo de la Ciudad para su restauración posterior y acoplamiento en un soporte neutro y transportable.

En los paramentos superiores, sobre las arcadas de la nave central, se conservaban, en regular estado, las pinturas al temple-cola consistentes en iconografias populares de los siglos XVII y XVIII.

Tales trabajos pictóricos alegóricos y conmemorativos tienen desigual valor artístico, nunca notable, pero forman parte consustancial de la "atmósfera" histórica del edificio, de forma que han sido conservados adecuadamente por especialistas

Como se cietaila en el texto complementario se ha efectuado la consolidación del soporte, que es un grueso revoco de mortero de cal hidráulica con yeso como acelerador de fraguado en grandes proporciones, lo que, a la larga, produce un efecto expansivo del material y su cuarteamiento, procediéndose, tras esto, a limpiar y consolidar la obra pictórica tal como ha llegado a nuestros días, sin interpretaciones o manipulaciones reveladoras de los repintes sucesivos o pretendidamente correctores. En aquellas lagunas ocasionadas por los empotramientos de tirantes de madera, impuestos para el arriostramiento de los muros sobre las arcadas de la nave central o bien por pérdidas localizadas, se ha procedido a reintegraciones con métodos de trattegio a regatino, mientras que en las pérdidas parciales se ha optado por veladura de mancha neutra. De forma científica se ha practicado una documentación detallada, de la situación previa y de los momentos de la actuación conservadora, con auxilio de técnicas de observación -fotografía sensible al espectro ultravioleta, etc.-, un análisis físico-químico de los pigmentos y aglutinantes, para determinar la naturaleza de los materiales existentes y, así, optar con certeza por el material consolidador de soporte y capa pictóricos, y 
después aplicar la protección final, de modo que nunca impida la actuación futura.

Otro de los oficios, cuyo tratamiento ha sido valorado con atención, es el de la cerrajería incorporada al edificio con un material contemporáneo, industrial, que exige un ajuste y elaboración esmerado, de forma análoga a lo que correspondía, en su etapa, a la mejor tradición de la forja gótica valenciana. Por ello se ha elegido la perfilería calibrada maciza, con un número reducido y recurrente de tamaños de perfilería básica, que se han usado tanto para la cerrajería de refuerzo como para la de cerramiento cuyo tratamiento de protección pictórica se ha diferenciado:

en la cerrajería de refuerzo estructural, cuyas piezas de mayor dimensión pertenecen al dominio del acero laminado y el resto es perfilería calibrada, se ha empleado una coloración diferenciada, pero muy entonada con los fondos de las fábricas,

en la cerrajería de cerramiento, como carpintería que recibe el vidrio correspondiente a los requerimientos de protección, se ha utilizado perfilería calibrada maciza, con un tratamiento valorativo de la textura propia en tono negro-azulado.

\section{Conclusión}

Ya, en la actualidad, el edificio está dedicado a la exhibición de exposiciones, preferentemente escultóricas, gestionadas por el Ayuntamiento y la Generalitat Valenciana.
El Almudín de Valencia es una propiedad municipal desde su origen. La obra restauradora tiene su razón en el convenio suscrito en 1991 entre el Ayuntamiento de la ciudad y la empresa FCC Medio Ambiente, como patrocinadora y titular del encargo a la sociedad de profesionales Arquitectura i Iniciatives per a la Ciutat de los trabajos de documentación histórica, arqueológica y de redacción del proyecto y de la dirección y gestión de las obras, conducidos por los arquitectos Juan Añón Gómez y Rafael Martínez Sánchez y el ingeniero Antonio Carratalà López. Por parte del Ayuntamiento de Valencia, el Servicio deProyectos Urbanos asumía la función de coordinación general, con el arquitecto José $\mathrm{M}^{\mathrm{a}}$ Herrera García, también coautor del proyecto.

Como aparejadores de la obra, actuaron D. Rafael Navarro Arnau y D. Juan Rubio Martínez.

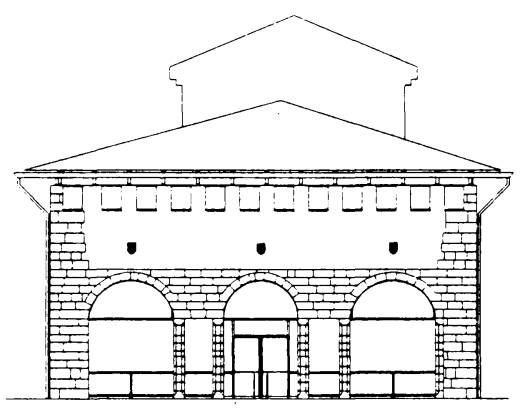

Restauración de El Almudín de Valencia.
(1) Antón Capitel: Los edificios en torno a patios: un método fundamental de hacer arquitectura en el período clásico. En Restauración Arquitectónica. Universidad de Valladolid. 1992. pp. 123-135.

(2) Vid. Guía Urbana de Valencia del Marqués de Cruilles. T.II. 1876.Copia Facsímil de Libr. París-Valencia. 1979. También citado este acontecimiento en V. Boix: Historia de la Ciudad y Reino de Valencia. T. 1. Imp. B. Monfort. Valencia. 1845. p. 426.

(3) Recientemente en Bérchez, J.: Arquitectura Renacentista Valenciana (1500-1570). Ed. Bancaja. Valencia, 1.994. Y en el prólogo de F. Marías de este libro, donde se da cierta carta de naturaleza a la coexistencia y fusión de opciones arquitectónicas: entre los modos asentados en la tradición técnica del gótico y aquéllos procedentes de las nuevas ideas transportadas desde Italia. pp. 16-22 y 52-54.

(4) Vid. P. H. Sholdfield: La Teoría de la proporción en arquitectura. Ed. Labor. Barcelona 1971. También la obra citada más adelante de R. Wittkower: Los fundamentos de la arquitectura en la edad del humanismo
(5) Además del comentario de la nota anterior, son sugerentes las referencias contenidas en V. Nieto: Renovación e indefinición estilística, 1488-1526, dentro de la obra Arquitectura del Renacimiento en España, 1488-1599, junto con A. J. Morales y F. Checa, Ed. Cátedra. Madrid, 1989.

(6) Ésta es la gran novedad que introdujo el vano serliano sobre el sistema clásico de ordenación basado en el ritmo de las columnas. Tal valoración aparece en la introducción de C. Sambricio: La fortuna de Sebastiano Serlio, en la edición de 1986 del Colegio Oficial de Aparejadores y Arquitectos Técnicos de Asturias, en dos tomos, uno en facsímil, de la edición veneciana de la obra del arquitecto boloñés, de 1600 , de Siete Libros, recopilada por Giovanni Domenico Scamozzi, traducida al castellano por F. Díaz Padilla.

(7) Sobre la teoría albertiana de la columna es imprescindible la contribución de R. Wittkower: Los fundamentos de la arquitectura en la edad del humanismo. Ed. N. Visión, B. Aires, 1958. Hay una reciente edición en Alianza Editorial, 1995. En ese texto hay una contribución fundamental sobre "el problema de la proporción armónica en arquitectura". 
(8) A nuestro juicio, el conocimiento de soluciones abovedadas por arista también presentes en la ciudad (Convento de Santo Domingo), evidencia el gran nivel técnico de la estereotomía de la piedra que significaría la adecuada preparación a la recepción del nuevo lenguaje renacentista. Si observamos el tratado de Alonso de Vandelvira, en la solución descrita para el arco en rincón de claustro, aparece prácticamente un análogo despliegue técnico, que, inequívocamente, valoramos en los arcos descritos del Almudín de Valencia como obra singular.

(9) Vid. Marqués de Cruilles: Guía Urbana de Valencia. T. II. 1876 , p. 19. Posiblemente se refiere al estado anterior a 1874 , ya que refiere acontecimientos en la ciudad hasta 1873.

(10) Se trata de aplicar una corteza de mezcla de cal, yeso y arena (con gran proporción de yeso en nuestro caso), para ayudar a la conservación y arreglo de las paredes. En ocasiones, se terminaba con estuco fino. La manualística del s. XVIII, de tradición vitrubiana, difundía estas técnicas de la albañilería tradicional, como el caso del Compendio de Perrault, traducido al castellano por J. Castañeda (1761), o el Arte de la Albañilería de J. de Villanueva (1827), por ejemplo.

(11) Vid. A. Gonzarez: Por una metodología de la intervención en el patrimonio arquitectónico como documento y como objeto arquitectónico. Rev. Fragmentos $n^{\circ} 6$. Ministerio de Cultura. 1985. También podemos encontrar argumentadas reflexiones sobre la influencia del espíritu de la época en Solá-Morales, I: Teorías de la intervención arquitectónica. Rev. Quaderns no 155. Barcelona. 1982. y también en A. Capitel: El tapiz de Penélope (Apuntes sobre las ideas de restauración e intervención arquitectónica). Rev. Arquitectura $\mathrm{n}^{\circ} 244$. Madrid. 1983.

(12) Vid. Estudio Geotécnico Estructural del Edificio del Almudín de Valencia. GEOCISA.

Mayo 1991. Por encargo del Servicio de Proyectos Urbanos del Ayuntamiento de Valencia.

(13) Estas piezas de sección aproximadamente rectangular, adoptan una rugosidad y traban con la fábrica antigua con un cajeado manual previo, ejecutado con gran precaución. El material ha consistido en hormigón blanco armado. En el resto de operaciones de refuerzo de fábricas, sin embargo, el recurso generalizado a los morteros de cal y arena seleccionada ha sido el procedimiento utilizado, que garantiza, como se sabe, la continuidad de comportamiento mecánico entre materiales antiguos y nuevos.
(14) Estos tirantes, cuya sección cruciforme no es constante, se apoyan en unos perfiles HEB160, anclados continuamente a los muros, para absorber los esfuerzos puntuales que no pueden soportar directamente las fábricas por su propia naturaleza.

(15) Ibid. nota 12.

(16) Vid. Fernández Paris, J. M.: Valoración del Estado de alteración de los materiales pétreos en los monumentos. INTEMAC. Madrid. 1982

(17) Ibid. Nota 12.

(18) Vid. el interesante trabajo del prof. Ortega Andrade: Humedades en la edificación. Sevilla. 1989.

(19) Ha constituido una valiosa orientación el trabajo aplicado de F. Font y P. Hidalgo: El Tapial, una tècnica constructiva mil.lenària. Castelló. 1991. También contienen aspectos interesantes las siguientes contribuciones, seleccionadas entre un dossier temático facilitado por INTEMAC: W. Castillo: El reforzamiento estructural de edificaciones de tapia: un caso de los Andes venezolanos. Seminario latinoamericano de construcciones sismorresistentes. Lima. 1983.- G. Bauluz y P. Bárcena: Bases para el diseño y construcción con tapial. - J..J. Momblanch: Arquitectura y sistemas constructivos en Al-Andalus. Tribuna de la Construcción. 1992. Finalmente, no debemos olvidar los últimos trabajos de Ignacio Gárate sobre las artes de la cal.

(20) Vid. Giuffré, Antonino: Letture sulla Meccanica delle Murature Storiche. Edizioni Kappa. Roma 1991

(21) Su gran obra Traité théorique et pratique de l'art de bâtir (1802), trasciende la tratadística anterior que había considerado los aspectos materiales del arte.

(22) Como ejemplo, sirva citar aquí a título de anécdota un manual usual en nuestro país a final de siglo pasado: Formulario del Constructor. Tablas, Fórmulas, Relaciones y Procedimientos Usuales y Prácticos de las Ciencias Aplicadas a la Construcción. Por Leoncio de la Bárcena, Madrid, 1870, que dedica su Capítulo III a los espesores de los muros.

(23) Vid. V. Melió Uribe: La Junta de Murs y Valls. Ed. Consell Valencià de Cultura. Serie Minor. Generalitat Valenciana. 1991. 


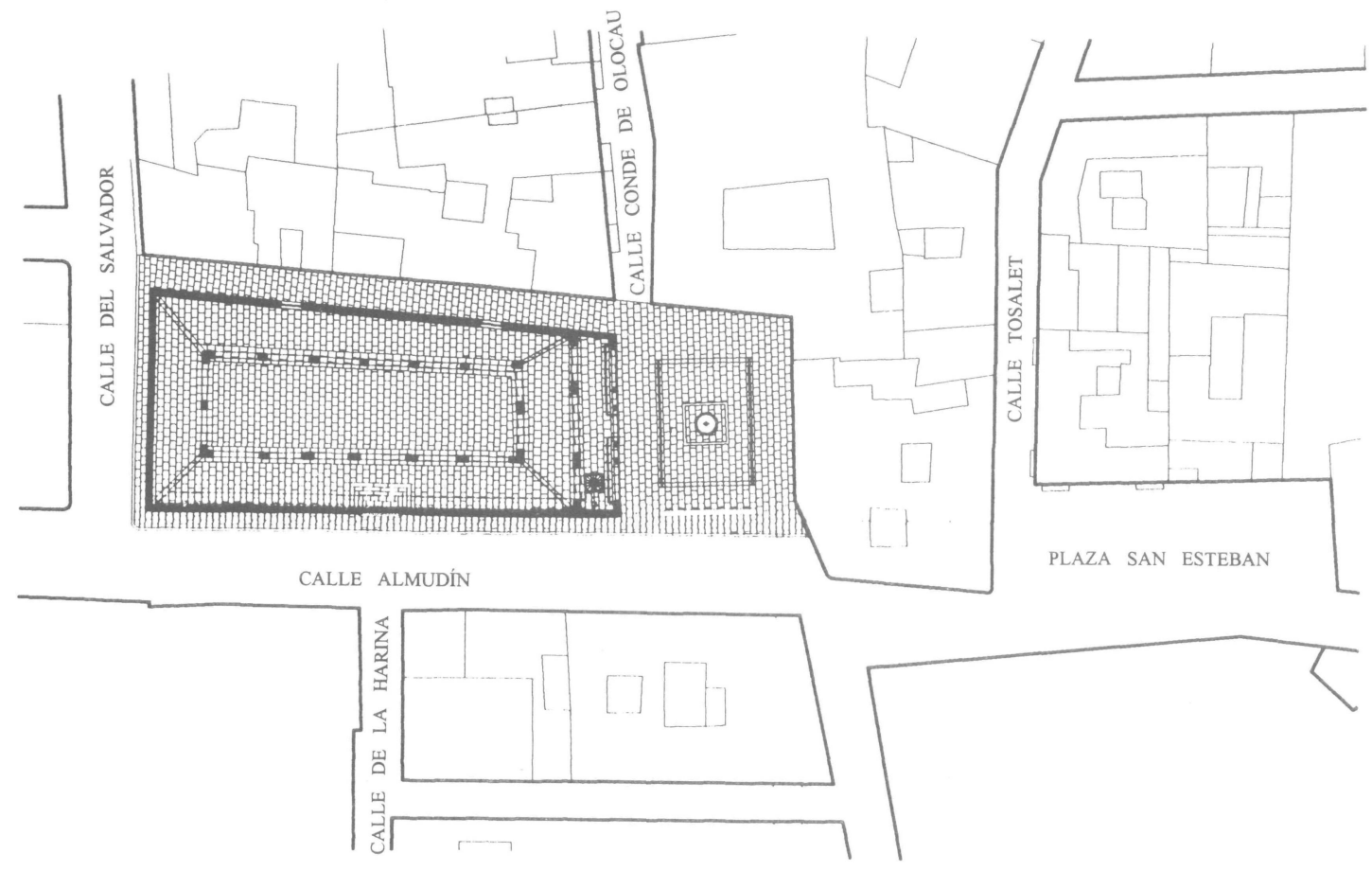

Planta general.
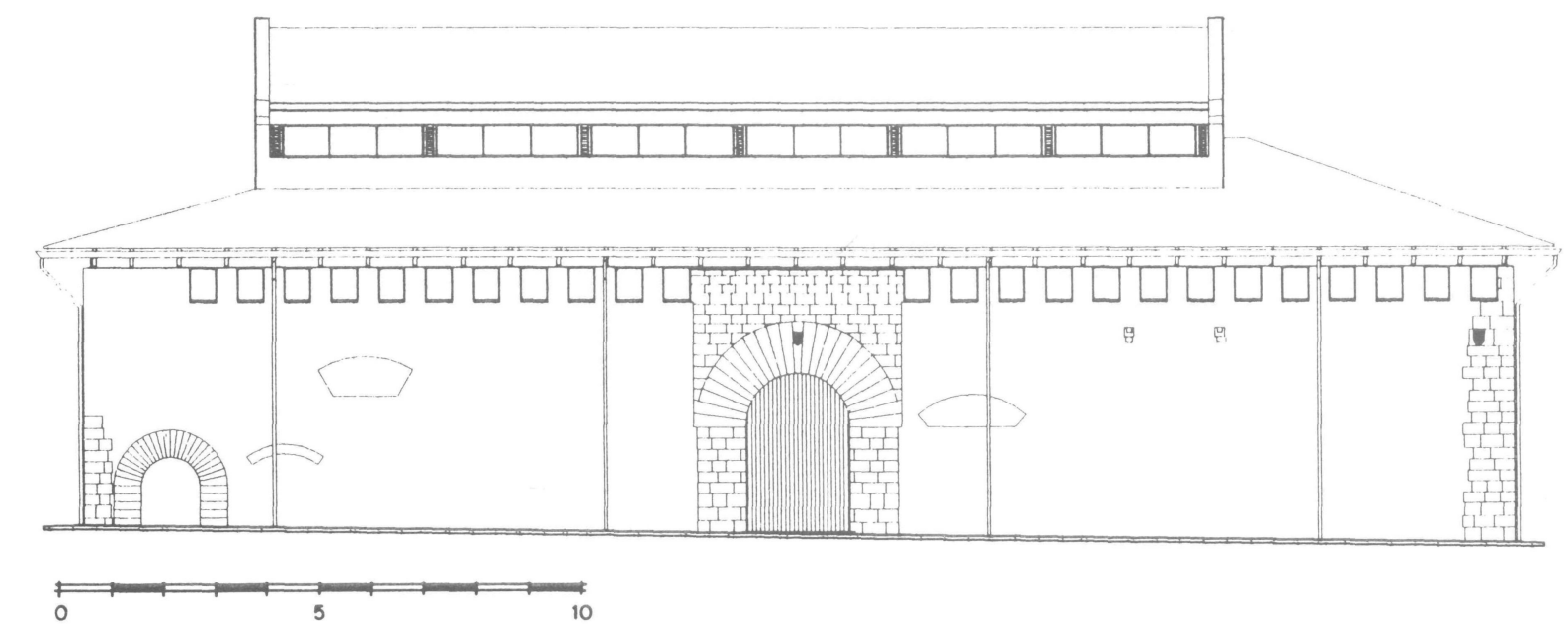

Fachada calle Almudin.

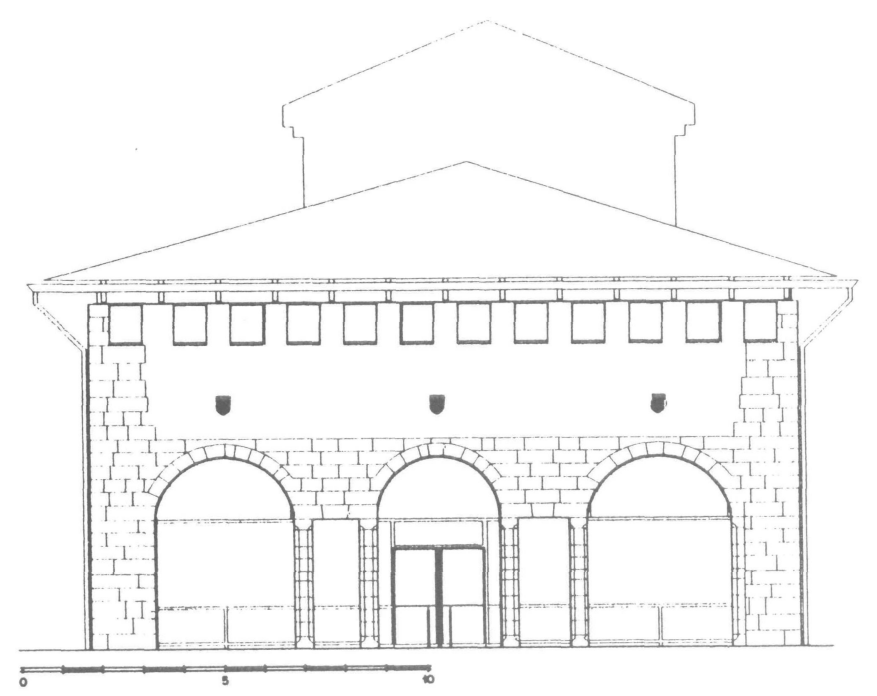

Fachada plaza de San Luis Beltrán.

(c) Consejo Superior de Investigaciones Científicas 

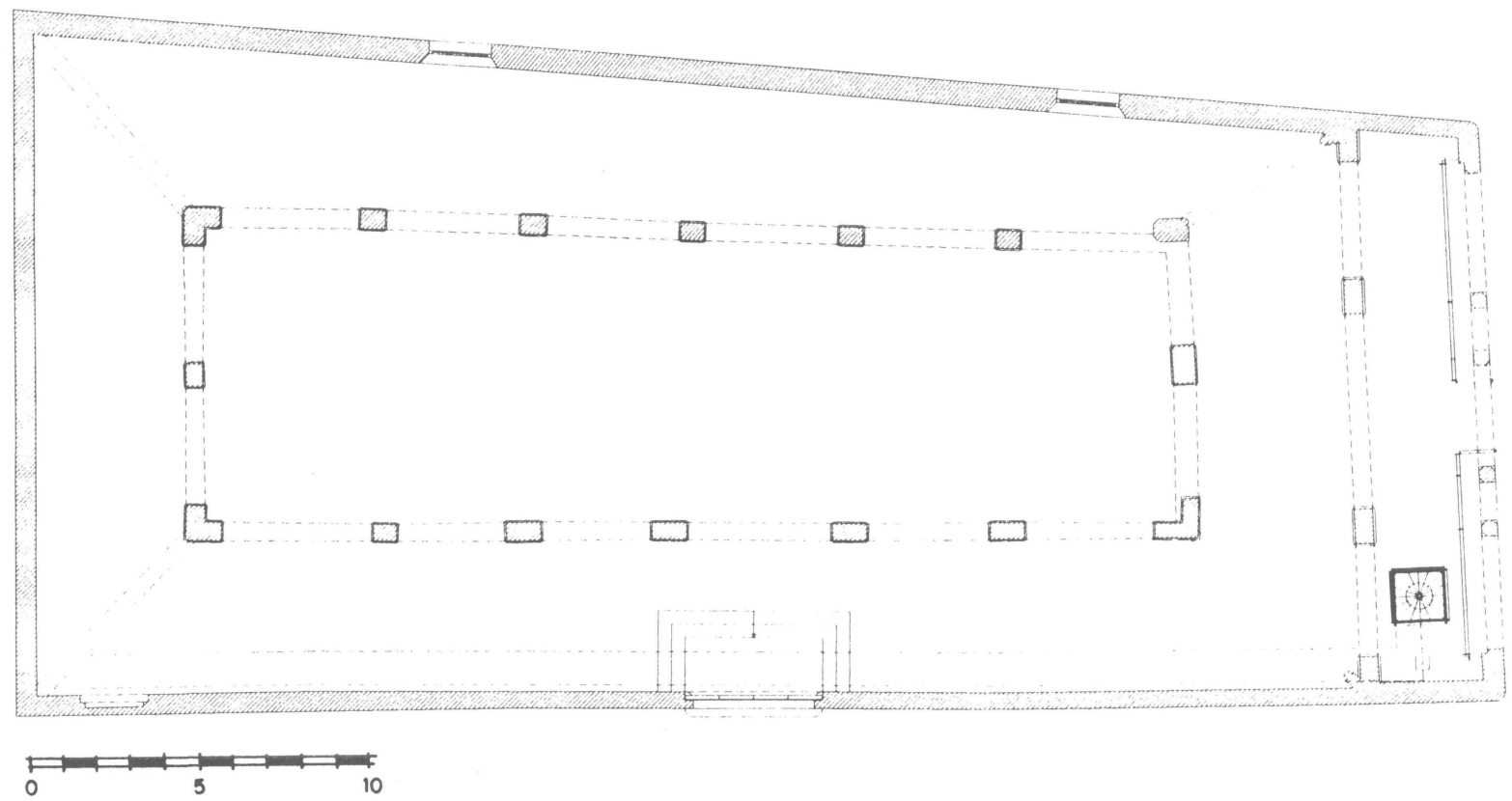

Planta proyecto.
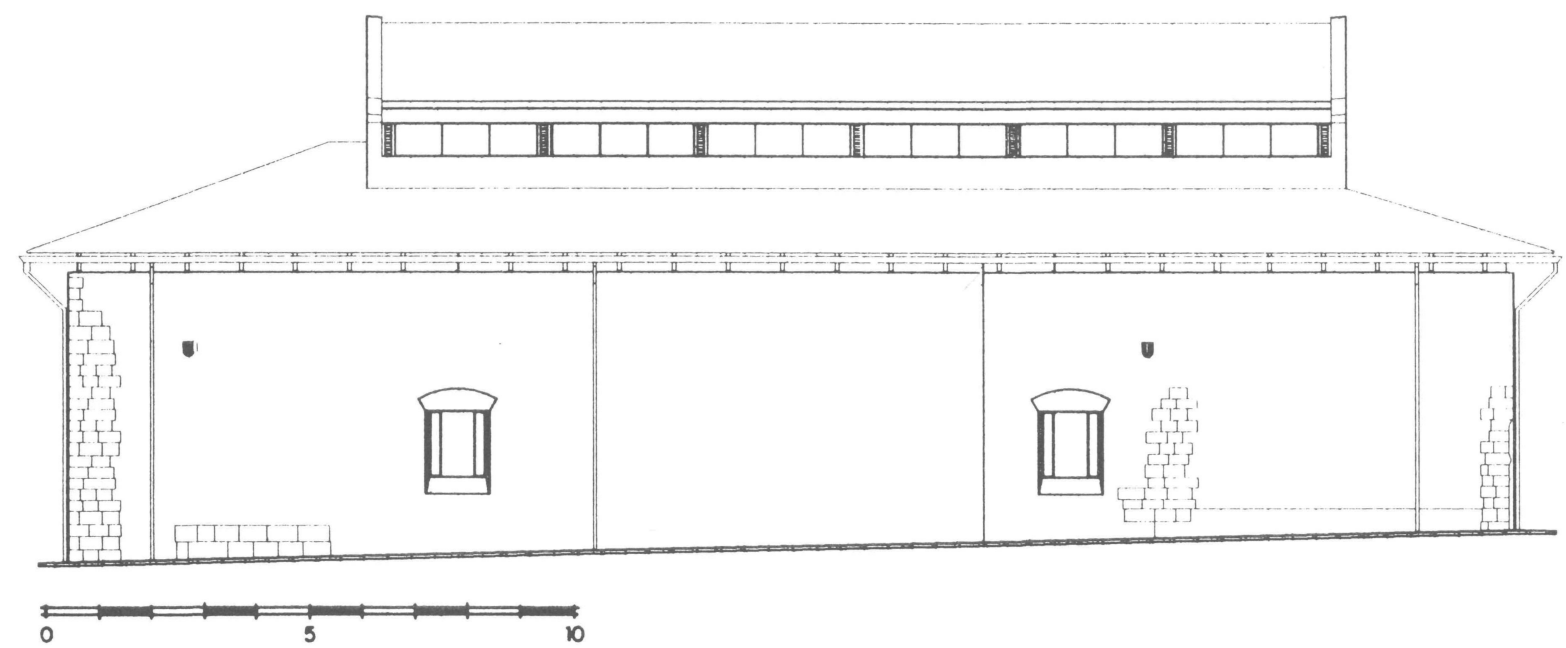

Fachada calle Angosta del Almudin.
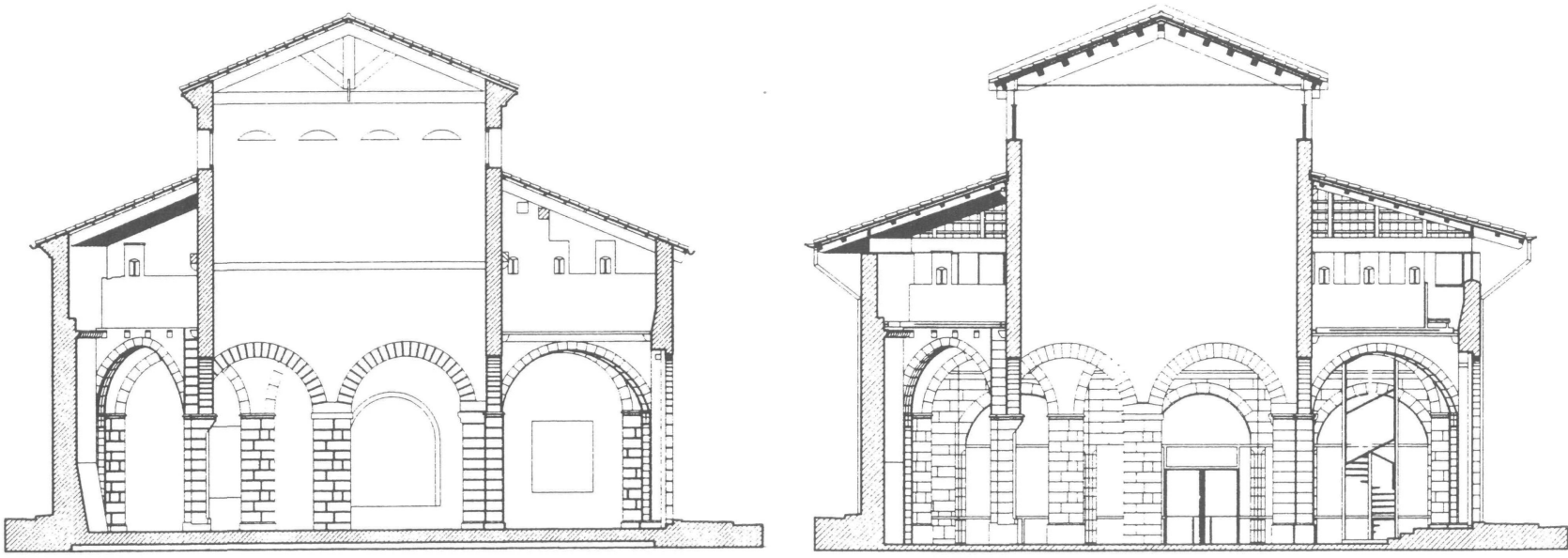

Sección transversal estado actual.

Sección transversal proyecto.

(c) Consejo Superior de Investigaciones Científicas 


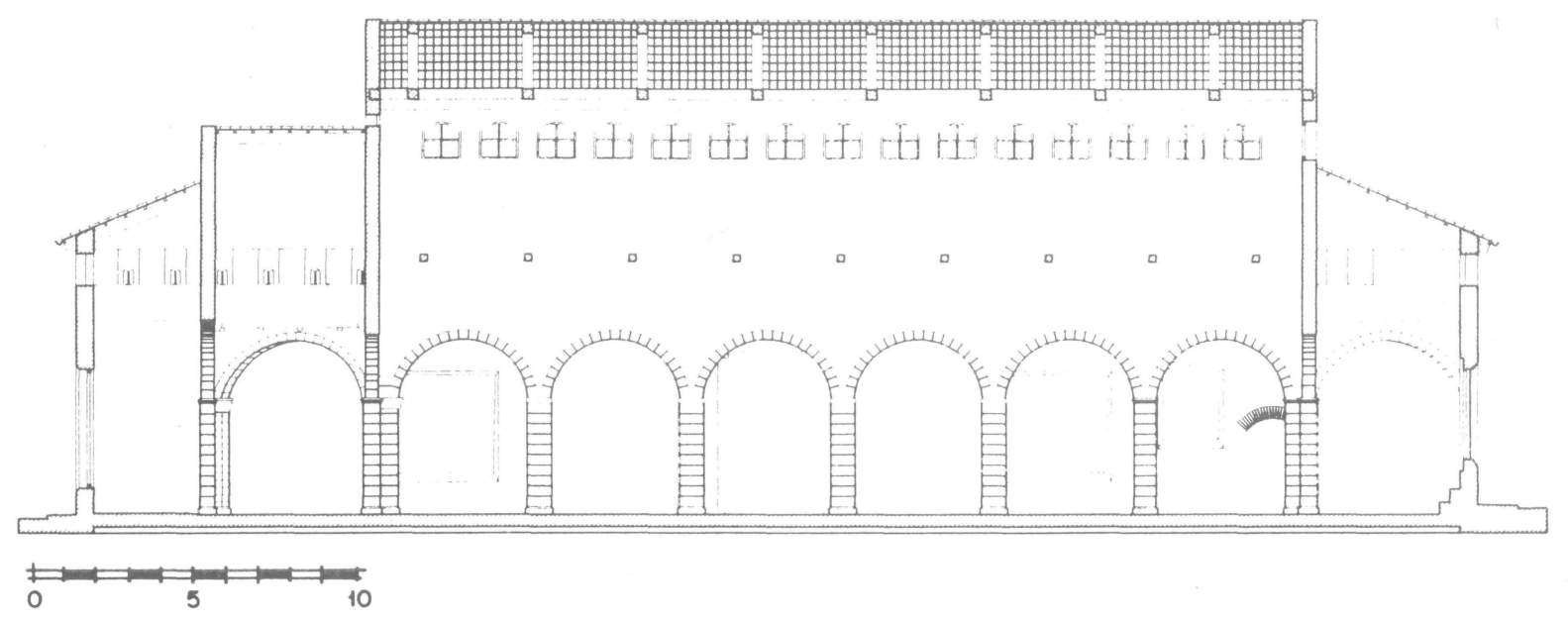

Sección longitudinal estado actual.

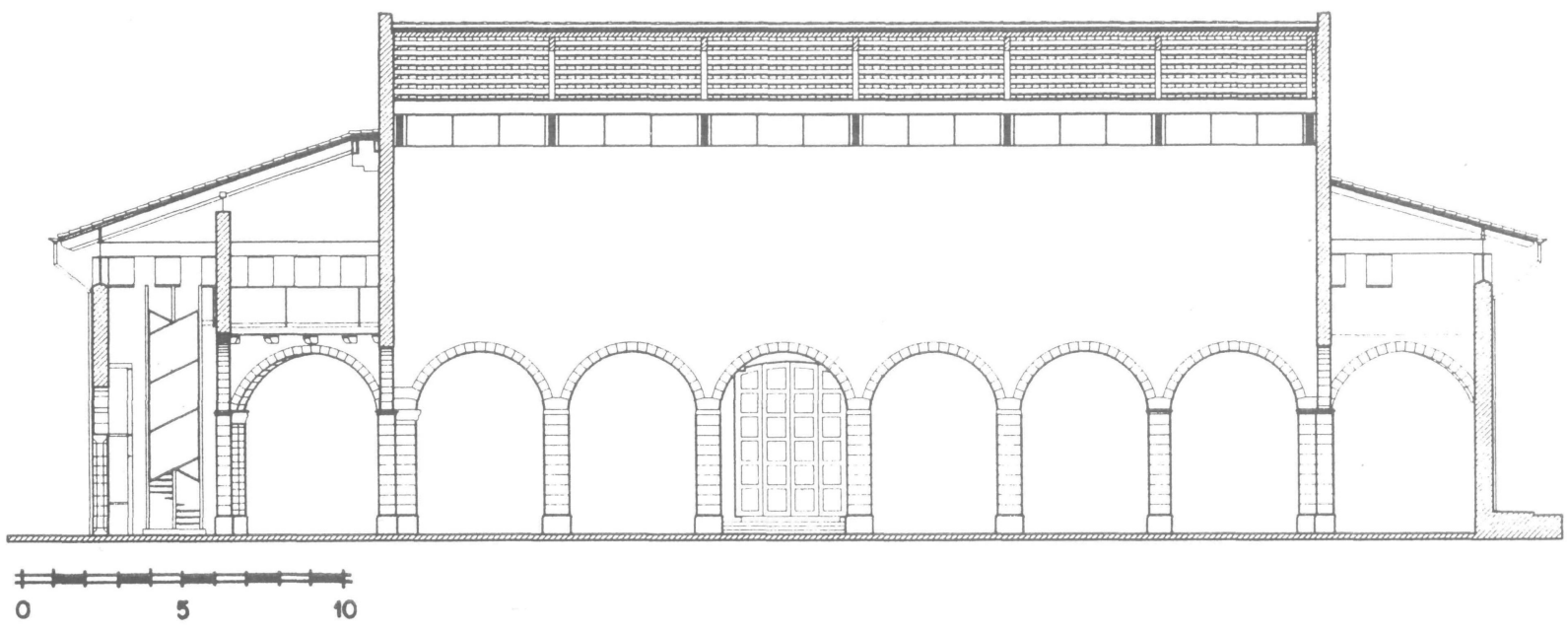

Sección longitudinal proyecto. 
TEJA ARABE

PLACA IMPERMEABLE.

HORMIGON CON ARLITA Y MALLA ELECTROSOLDADA.

TABLERO DE BARDO MACHIEMBRADO $80 \times 25 \times 3.5 \mathrm{~cm}$

CORREA DE MADERA LAMINADA ENCOLADA.

ANCLAJE DE ACERO INOXIDABLE.

CERCHA DE MADERA LAMINADA ENCOLADA.

TIRANTE DE ACERO INOXIDABLE $\varnothing 22 \mathrm{~mm}$

PERFIL METALICO IPE-450

CARPINTERIA METALICA PLETINA CALIBRADA $60 \times 12 \mathrm{~mm}$.

VIDRIO STADIP $4+4 \mathrm{~mm}$

PIE DERECHO HEB 100.

PROYECTOR MSNF 100 PHILIPS LAMP. SDWT 100W.

ZUNCHO DE HÓRMIGON ARMADO.

FABRICA DE TAPIA REAL EXISTENTE.
16. SOPORTE ANGULAR $120 \times 120 \times 12 \mathrm{~mm}$.

17. FABRICA DE LADRILLO MACIZO EXISTENTE,

18. BARANDILLA Y PASARELA METALICA ACERO CALIBRADO.

19. BABERO DE PLOMO

20. CANECILLO DE PIEDRA EXISTENTE.

21. PAR DE MADERA LAMINADA ENCOLADA

22. CANALON DE CHAPA DE COBRE.

23. BAJANTE DE COBRE DE $\emptyset 100 \mathrm{~mm}$

24. PERFIL METALICO HEB-160

25. TIRANTE DE TRACCION- COMPRESION DE PLATABANDA CALIBRADA $10 \times 160 \mathrm{~mm}$

26. PAVIMENTO CON BALDOSAS DE PIEDRA ULLDECONA DE $80 \times 60 \times 4 \mathrm{~cm}$.

27. REVESTIMIENTO DE PELDAÑOS CON BALDOSAS DE PIEDRA ULLDECONA DE $6 \mathrm{~cm}$ DE ESPESOR

28. MORTERO BASTARDO

29. SOLERA DE HORMION H-150 DE $20 \mathrm{~cm}$

30. MALLAZO DE $15 \times 15 \times 4$.

31. LAMINA IMPERMEABILIZANTE POLIMERICA.

32. HORMIGONDE LMPIEZA H-50.

33. ZAHORRA ARTIFICIAL COMPACTADA

4. FORMACION DE PELDAÑOS DE HORMIGON EN MASA

5. LOSA DE HORMIGON H-150.

36. HORMIGON CICLOPEO EN RECALCES Y ARRANQUES DE MURO.

37. ZAPATA CORRIDA DE HORMIGON ARMADO H-175 EN RECALCES.

38. LOSA DE PIEDRA DE ULLDECONA DE $5 \mathrm{~cm}$ DE ESPESOR.

39. LECHO DE ARENA.

40. BORDILLO DE PIEDRA DE ULLDECONA DE $20 \times 25 \mathrm{~cm}$

41. HORMIGON H-100.

42. TUBERIA DE HOMIGON POROSO $\emptyset 150 \mathrm{~mm}$ DRENAJE PERIMETRAL

43. APLIQUE MURAL IODINE LAMP. MHN-TD 7OW.

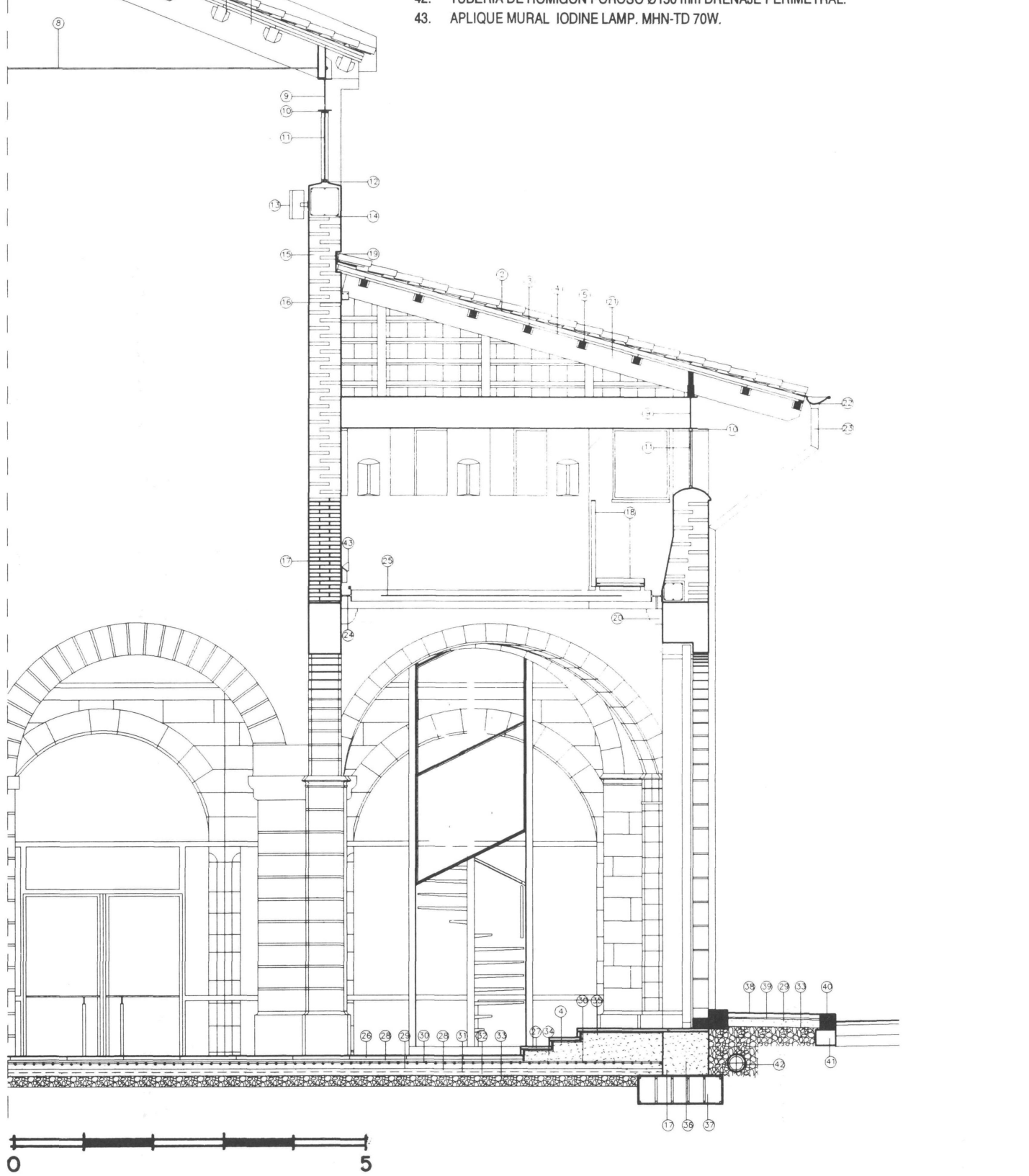

Sección constructiva proyecto. 